\title{
Sympathetic Sprouting Drives Hippocampal Cholinergic Reinnervation That Prevents Loss of a Muscarinic Receptor- Dependent Long-Term Depression at CA3-CA1 Synapses
}

\author{
Cary L. Scheiderer, ${ }^{2}$ Eve McCutchen, ${ }^{1}$ Erin E. Thacker, ${ }^{1}$ Krystyna Kolasa, ${ }^{3,4}$ Matthew K. Ward, ${ }^{5}$ Dee Parsons, ${ }^{3,4}$ \\ Lindy E. Harrell, ${ }^{3,4,6}$ Lynn E. Dobrunz, ${ }^{1,2,3}$ and Lori L. McMahon ${ }^{1,2,3}$ \\ Departments of ${ }^{1}$ Physiology and Biophysics and ${ }^{2}$ Neurobiology, ${ }^{3}$ Alzheimer's Disease Research Center, Departments of ${ }^{4}$ Neurology and ${ }^{5}$ Psychology, and \\ ${ }^{6}$ Veterans Affairs Medical Center, University of Alabama at Birmingham, Birmingham, Alabama 35294
}

\begin{abstract}
Degeneration of septohippocampal cholinergic neurons results in memory deficits attributable to loss of cholinergic modulation of hippocampal synaptic circuits. A remarkable consequence of cholinergic degeneration is the sprouting of noradrenergic sympathetic fibers from the superior cervical ganglia into hippocampus. The functional impact of sympathetic ingrowth on synaptic physiology has never been investigated. Here, we report that, at CA3-CA1 synapses, a Hebbian form of long-term depression (LTD) induced by muscarinic $M_{1}$ receptor activation (mLTD) is lost after medial septal lesion. Unexpectedly, expression of mLTD is rescued by sympathetic sprouting. These effects are specific because LTP and other forms of LTD are unaffected. The rescue of mLTD expression is coupled temporally with the reappearance of cholinergic fibers in hippocampus, as assessed by the immunostaining of fibers for VAChT (vesicular acetylcholine transporter). Both the cholinergic reinnervation and mLTD rescue are prevented by bilateral superior cervical ganglionectomy, which also prevents the noradrenergic sympathetic sprouting. The new cholinergic fibers likely originate from the superior cervical ganglia because unilateral ganglionectomy, performed when cholinergic reinnervation is well established, removes the reinnervation on the ipsilateral side. Thus, the temporal coupling of the cholinergic reinnervation with mLTD rescue, together with the absence of reinnervation and mLTD expression after ganglionectomy, demonstrate that the autonomic-driven cholinergic reinnervation is essential for maintaining mLTD after central cholinergic cell death. We have discovered a novel phenomenon whereby the autonomic and central nervous systems experience structural rearrangement to replace lost cholinergic innervation in hippocampus, with the consequence of preserving a form of LTD that would otherwise be lost as a result of cholinergic degeneration.
\end{abstract}

Key words: synaptic plasticity; hippocampus; LTD; muscarinic acetylcholine receptor; G-protein-coupled receptors; superior cervical ganglion

\section{Introduction}

Intact cholinergic innervation is required for some forms of hippocampal-dependent memory processing (Hasselmo, 1999), probably because it modulates excitatory glutamate transmission (Rovira et al., 1983; Huerta and Lisman, 1993; Fernandez De Sevilla and Buno, 2003). Activation of muscarinic acetylcholine receptors ( $\mathrm{mAChRs}$ ) decreases presynaptic glutamate release and directly induces or modulates long-term potentiation (LTP) and long-term depression (LTD) at hippocampal CA3-CA1 synapses (Valentino and Dingledine, 1981; Auerbach and Segal, 1994,

Received Aug. 3, 2005; revised Feb. 7, 2006; accepted Feb. 7, 2006

This work was supported by National Institutes of Health (NIH) National Institute on Aging (NIA) Award AG21612 (L.L.M.), NIH National Research Service Award NS045469 (C.L.S.), NIH NIA Award P50AG16582 to the University of Alabama at Birmingham Alzheimer's Disease Research Center, and a Veterans Affairs Merit Award (L.E.H.). We thank Drs. Julie Kauer, Robin Lester, and Diana Pettit for helpful comments on previous versions of this manuscript, Caroline Smith for assistance with figure preparation, and Albert Tousson for assistance with imaging.

Correspondence should be addressed to Dr. Lori L. McMahon, Department of Physiology and Biophysics, University of Alabama at Birmingham, 1918 University Boulevard, MCLM 964, Birmingham, AL 35294-0005. E-mail: mcmahon@physiology.uab.edu.

DOI:10.1523/JNEUROSCI.5507-05.2006

Copyright $\odot 2006$ Society for Neuroscience $\quad$ 0270-6474/06/263745-12\$15.00/0
1996; Kirkwood et al., 1999; Kremin et al., 2005; Shinoe et al., 2005). Because long-term alterations in efficacy of glutamate transmission contribute to memory mechanisms (Bliss and Collingridge, 1993; Malenka and Bear, 2004), induction of long-term synaptic changes by cholinergic receptors likely underlies the cholinergic dependence of normal memory processing. Hippocampal cholinergic innervation, originating in medial septum, degenerates in Alzheimer's disease (AD), which is likely causal to memory deficits in affected patients (Kesner et al., 1989). In fact, the severity of memory deficit is strongly correlated with the degree of cholinergic cell loss (Bierer et al., 1995). Moreover, blockade of the $M_{1}$ receptor subtype of $m A C h R s$ results in memory impairment in rats and humans that mimics memory deficits in AD (Drachman and Leavitt, 1974; Ghelardini et al., 1999; Anagnostaras et al., 2003; Atri et al., 2004).

A remarkable consequence of death of septohippocampal cholinergic neurons, in both humans with $\mathrm{AD}$ and rodent models of cholinergic degeneration, is the ingrowth of noradrenergic sympathetic axons into hippocampus (Loy and Moore, 1977) (for review, see Crutcher, 1987). These axons originate in the superior cervical ganglia (SCG) and normally innervate only the 
cerebral vasculature. Their sprouting into hippocampus is stimulated by accumulation of nerve growth factor (NGF) and can be prevented by bilateral superior cervical ganglionectomy or infusion of anti-NGF antibodies (Collins and Crutcher, 1985; Crutcher, 1987).

The functional impact of sympathetic sprouting on hippocampal synaptic function has never been investigated. Biochemical analysis shows that hippocampal cholinergic denervation reduces carbachol (CCh) stimulated phosphoinositide (PI) hydrolysis and protein kinase $\mathrm{C}$ (PKC) activation, mediated by combined activation of $\mathrm{G}_{\mathrm{q}}$-coupled $\mathrm{M}_{1}$ and $\mathrm{M}_{3}$ receptors, to approximately one-half of that measured in control animals (Harrell et al., 1995; Ayyagari et al., 1996; Kolasa et al., 1997, 2000). This deficit results from inefficient $\mathrm{mAChR}-\mathrm{G}$-protein coupling rather than from changes in mAChR expression (Harrell et al., 1995; Ayyagari et al., 1996; Kolasa et al., 1997, 2000). Surprisingly, CCh-stimulated PI hydrolysis is restored to normal levels when sprouting from the SCG is allowed to occur (Harrell et al., 1995; Kolasa et al., 1997), suggesting that sprouting restores mAChRG-protein coupling.

How the increase in adrenergic sympathetic innervation rescues cholinergic function is unresolved. It is also not known whether the decreased $\mathrm{mAChR}$ signaling after denervation is significant enough to interfere with normal mAChR-mediated modulation of hippocampal synaptic function. Furthermore, whether the normalization of $\mathrm{mAChR}-\mathrm{G}$-protein coupling by sympathetic sprouting will affect or modulate transmission at hippocampal synapses is untested.

Here, we show that, at CA3-CA1 synapses, hippocampal cholinergic denervation causes a loss of a cholinergic-dependent form of LTD. Remarkably, expression of this plasticity is rescued by sympathetic sprouting. This rescue is precisely timed with appearance of axons immunopositive for the vesicular acetylcholine transporter (VAChT), and their presence is completely dependent on sprouting from the SCG. Our results suggest a powerful communication between the CNS and the autonomic nervous system, whereby the autonomic nervous system is directly responsible for reinnervating hippocampus with cholinergic fibers, which preserves expression of a form of synaptic plasticity. This mechanism highlights the ability of the nervous system to maintain homeostasis in the face of neurodegeneration so that normal synaptic function can continue.

\section{Materials and Methods}

Experiments were conducted with an approved protocol from the University of Alabama at Birmingham Institutional Animal Care and Use Committee, in compliance with National Institutes of Health guidelines.

Electrophysiology. All experiments were performed using standard methods (Scheiderer et al., 2004). Hippocampal slices $(400 \mu \mathrm{m})$ were prepared from 3- to 21-week-old Sprague Dawley rats. Animals were anesthetized with halothane and decapitated. Coronal slices from the dorsal hippocampus were cut using a vibratome in a modified artificial CSF (aCSF) (in mM): $85 \mathrm{NaCl}, 2.5 \mathrm{KCl}, 4 \mathrm{MgSO}_{4}, 0.5 \mathrm{CaCl}_{2}, 1.25$ $\mathrm{NaH}_{2} \mathrm{PO}_{4}, 25 \mathrm{NaHCO}_{3}, 25$ glucose, 75 sucrose, 2 kynurenic acid, and 0.5 ascorbate. After a $30 \mathrm{~min}$ postslice incubation, slices were stored in a standard aCSF (in mm): $119 \mathrm{NaCl}, 2.5 \mathrm{KCl}, 2.5 \mathrm{CaCl}_{2}, 1.3 \mathrm{MgSO}_{4}, 1$ $\mathrm{NaH}_{2} \mathrm{PO}_{4}, 26 \mathrm{NaHCO}_{3}$, and 10 glucose, pH 7.4, containing $2 \mathrm{~mm}$ kynurenic acid. For recordings, slices were transferred to a submersion recording chamber and continuously perfused at 3-4 $\mathrm{ml} / \mathrm{min}$ with oxygenated standard aCSF (without kynurenic acid) at $29^{\circ} \mathrm{C}-31^{\circ} \mathrm{C}$. CA1 extracellular dendritic field potentials were recorded with an Axopatch 2B amplifier (Molecular Devices, Sunnyvale, CA) using standard methods (Scheiderer et al., 2004). A stainless steel bipolar stimulating electrode (FHC, Bowdoinham, ME) was placed in stratum radiatum to stimulate Schaffer collateral axons, and a glass microelectrode filled with $2 \mathrm{M}$
$\mathrm{NaCl}$ was used to record extracellular dendritic field potentials in CA1 stratum radiatum. The stimulus intensity was adjusted to yield a baseline field EPSP (fEPSP) of $0.8-1.0 \mathrm{mV}$, and events were collected at $0.2 \mathrm{~Hz}$. The initial slope of the synaptic response was measured and plotted versus time, with each point representing the average of five consecutive data points. Data were acquired and stored using custom software written in Labview (a gift from Richard Mooney, Duke University, Durham, NC). Data are presented as mean \pm SEM. Statistical significance was determined using Student's $t$ test, and results were considered significant at $p<0.05$.

To characterize the properties of muscarinic LTD (mLTD), electrophysiological recordings were performed in acute slices prepared from 3 to 4-week-old animals. In most experiments, mLTD was induced using a 10 min bath application of $50 \mu \mathrm{M} \mathrm{CCh}$ (Sigma, St. Louis, MO), consistent with procedures published previously (Kirkwood et al., 1999). As shown in Figure 1, other drug application methods could also induce mLTD, but the $10 \mathrm{~min}$ application induced reliable and robust plasticity, so this protocol was adopted for the majority of experiments unless indicated otherwise. For experiments using the $M_{1}$ toxin to block $M_{1}$ receptors, slices were incubated for $\geq 1 \mathrm{~h}$ in aCSF containing $100 \mathrm{nM} \mathrm{M}_{1}$ toxin (MTx-7; Peptides International, Louisville, KY) before being transferred to a recording chamber. The effects of hippocampal cholinergic denervation and sympathetic ingrowth on mLTD expression were assessed by lesioning the medial septum, with either electrolytic stimulation or intraseptal injection of the specific cholinergic immunotoxin 192 IgGsaporin, with and without bilateral superior cervical ganglionectomy to either prevent or allow sympathetic ingrowth, respectively (for specifics, see below). The effects of sympathetic sprouting on MLTD expression were assayed at 4 weeks after electrolytic lesion and 12 weeks after 192 IgG-saporin lesion because ingrowth is well established at these times (Loy and Moore, 1977; Crutcher, 1987; Harrell et al., 1995, 2001). To assess the time course in which cholinergic denervation and hippocampal sympathetic ingrowth affect mLTD expression, only electrolytic lesions were used, because these lesions result in a more defined timing of cholinergic cell death. In these studies, electrophysiology and immunohistochemistry were performed 3 and $10 \mathrm{~d}$ after electrolytic lesion. Noradrenergic (NE) LTD was induced by a $10 \mathrm{~min}$ application of the $\alpha 1$ agonist phenylephrine $(100 \mu \mathrm{M})$ (Scheiderer et al., 2004) and lowfrequency stimulation (LFS)-LTD was induced using $1 \mathrm{~Hz}$ stimulation for 15 min (Dudek and Bear, 1992). In the LTP experiments, the initial stimulus intensity was adjusted to produce a baseline fEPSP of $0.5 \mathrm{mV}$. The high-frequency stimulus (HFS) protocol used to induce LTP consisted of two $1 \mathrm{~s}$ trains of $100 \mathrm{~Hz}$ separated by $20 \mathrm{~s}$. The stimulus intensity was increased to $1.5 \times$ the baseline intensity during an HFS and returned to the baseline level after an HFS.

Medial septal lesions and superior cervical ganglionectomy. Hippocampal cholinergic denervation was performed using two methods to lesion the medial septum. The electrolytic stimulation method offers the advantage of a more defined timing of cholinergic cell death, but the lesion is not specific to cholinergic cells; use of the immunotoxin $192 \mathrm{IgG}$-saporin limits destruction to cholinergic neurons, but the degeneration takes a period of days to occur. For the initial studies assessing the effects of ingrowth, animals were killed at 4 weeks after electrolytic lesion (Loy and Moore, 1977; Crutcher et al., 1981, 1987) and at 12 weeks after lesion using the immunotoxin 192 IgG-saporin (Harrell et al., 2001), times at which ingrowth is well established. Note that many studies using 192 IgG-saporin to lesion medial septum wait just 2-6 weeks after lesion before commencing their studies; therefore, ingrowth is not present and does not affect their experimental outcomes (for example, see BergerSweeney et al., 1994; Heckers et al., 1994; Rossner et al., 1995). Animals were anesthetized with ketamine $(100 \mathrm{mg} / \mathrm{kg})$ and xylazine $(13 \mathrm{mg} / \mathrm{kg})$ administered intraperitoneally. For electrolytic lesion, a bipolar Tefloncoated stainless steel electrode was lowered stereotaxically into the medial septum, and current $(3 \mathrm{~mA} \times 25 \mathrm{~s})$ was passed through the electrode (Harrell et al., 1995; Kolasa et al., 1995, 1997). Sham lesioned animals underwent the same procedure, but no current was applied. For immunotoxin lesion, 192-IgG-saporin was injected stereotaxically using a Hamilton syringe ( $1 \mu \mathrm{g}$ of toxin in $2.0 \mu \mathrm{l}$ of PBS was injected over $5 \mathrm{~min}$ ) [Advanced Targeting Systems (San Diego, CA) lot numbers 21-107 and 
24-87] (Kolasa et al., 1995, 1997; Harrell et al., 2001). Sham lesioned animals underwent the same procedure, but $2.0 \mu \mathrm{l}$ of saline was injected instead of the immunotoxin. We were not concerned about the loss of GABAergic neurons by the toxin because intact $\mathrm{GABA}_{\mathrm{A}}$ receptormediated inhibition is not required for mLTD expression (see Fig. 1I), and several studies report that GABAergic neurons are mostly spared at concentrations close to or higher than those used in the current study (Berger-Sweeney et al., 1994; Heckers et al., 1994; Hortnagl and Hellweg, 1997; Gu et al., 1998; McGaughy et al., 2002). Superior cervical ganglionectomies were performed via a neck incision to expose the carotid arteries, followed by visualization and bilateral removal of the ganglia. Ganglionectomies were performed on the day of the septal lesion, except for experiments with unilateral ganglionectomy (see Fig. 7), which were performed at 4 weeks after electrolytic lesion. For sham ganglionectomies, the ganglia were exposed but not removed.

Analysis of all data were performed blind. Regarding the electrophysiology studies, experiments were performed in slices prepared from all animals that underwent the surgical procedures because at the time of acute slice preparation, it was not possible to know whether the lesion was complete. Experiments were discarded if there was a $>8 \%$ drift in baseline transmission or a larger than normal stimulus intensity was needed. Before data were collated into the final average, electrophysiology experiments from animals were discarded when immunohistochemical analysis of the medial septum indicated that the lesion was incomplete $(\sim 10 \%$ were incomplete with electrolytic stimulation and $30 \%$ were incomplete with the immunotoxin lesion). In studies using immunohistochemistry to assess the presence of sympathetic ingrowth, sections were only stained after first confirming the completeness of the lesions.

Before surgery, adult male Sprague Dawley rats (8 weeks old) were randomly assigned to four groups: (1) animals that underwent surgeries but no lesions were made (sham, control); (2) animals with cholinergic denervation and intact SCG to permit sympathetic sprouting; (3) animals with cholinergic denervation and bilateral superior cervical ganglionectomy to prevent ingrowth of sympathetic fibers; (4) animals with bilateral ganglionectomy and sham medial septal lesion. Data obtained from slices prepared from groups 1 and 4 were pooled, because there was no difference in mLTD observed between these groups. In addition, statistical analysis indicated no difference in mLTD expression in animals with electrolytic and saporin lesions; therefore, these data were also pooled. Data separated by lesion method are presented in supplemental Figure 3 (available at www.jneurosci.org as supplemental material). Student's $t$ test was used to compare results from lesioned and control animals. Significance was determined at $p<0.05$.

Histology. Lesions were confirmed histochemically in medial septum using the copper-thiocholine method to detect acetylcholinesterase, as described previously (Naik, 1963; Harrell et al., 1995, 2005; Kolasa et al., 1997; Harrell et al., 2001). To test for lesion completeness, tissue blocks containing the septum were resectioned into $20 \mu \mathrm{m}$ coronal sections using a cryostat. Sections (at $100 \mu \mathrm{m}$ intervals) were stained with cresyl violet and for acetylcholinesterase (AChE) using the copper thiocholine method (Naik, 1963). Care was taken to compare the same anatomical regions between animals. Lesions were considered complete only if AChE staining was absent. Data from animals with incomplete lesions were discarded. Example images demonstrating lesion completeness are shown in supplemental Figure 2 (available at www.jneurosci.org as supplemental material).

Immunohistochemistry. Animals were perfused with PBS, followed by $4 \%$ paraformaldehyde (PFA) in PBS. Brains were postfixed in 4\% PFA for $2 \mathrm{~h}$, and then transferred to a solution of $30 \%$ sucrose in PBS overnight. Tissue was resectioned to $40 \mu \mathrm{m}$ on a freezing microtome. Sections were washed three times for $10 \mathrm{~min}$ in PBS and then blocked in $10 \%$ normal donkey serum (NDS) in $0.3 \%$ Triton X-100 PBS for $1 \mathrm{~h}$. Primary antibodies were diluted in 5\% NDS in $0.3 \%$ Triton X-100 PBS [rabbit anti-tyrosine hydroxylase (TH), 1:400; goat anti-vesicular acetylcholine transporter (VAChT), 1:1000; all from Chemicon, Temecula, CA], applied to the free-floating sections, and incubated overnight at $4^{\circ} \mathrm{C}$. Slices were washed three times for 10 min with PBS followed by incubation with fluorescently labeled secondary antibodies (donkey anti-rabbit Al- exa 594 and donkey anti-goat Alexa 488; 1:200; Molecular Probes, Carlsbad, CA) for $1 \mathrm{~h}$ at room temperature. Slices were mounted on slides with Permafluor (Immunon, Pittsburgh, PA) and examined on a Leica (Nussloch, Germany) DM IRBE laser-scanning confocal microscope. Red and green channels were scanned sequentially, and $20 \mu \mathrm{m}$ stacks of images were obtained in the $z$-axis at a $0.8 \mu \mathrm{m}$ step size, averaging four scans per image. A maximum projection was created and used for quantification. VAChT-positive boutons were counted in a blind manner, with the criterion that at least four consecutive boutons must be observed to be classified as a fragment of axon and be counted. The entire field of view $(250 \times 250 \mu \mathrm{m})$ was analyzed. Staining of all animal groups (sham lesioned animals and animals with and without ingrowth) was done simultaneously to control for variability in the staining reaction, and both imaging and quantification were performed by an experimenter with no knowledge of the nature of the lesion.

\section{Results \\ Muscarinic $M_{1}$ receptors induce a Hebbian form of LTD at CA3-CA1 synapses}

In visual and perirhinal cortex, application of the nonselective cholinergic receptor agonist $\mathrm{CCh}$ induces LTD of glutamate transmission that requires activation of muscarinic $M_{1}$ receptors (Kirkwood et al., 1999; Massey et al., 2001). Here, in hippocampal slices, we show that a $10 \mathrm{~min}$ application of $50 \mu \mathrm{M}$ CCh elicits a transient depression of the dendritic CA3-CA1 fEPSP, consistent with earlier and more recent reports (Valentino and Dingledine, 1981; Auerbach and Segal, 1996; Kremin et al., 2005; Shinoe et al., 2005), which is followed by LTD after agonist washout (Fig. $1 A-D)$. The LTD can also be elicited with pulsatile CCh application ( $10 \mathrm{~ms}$ puffs, $1 \mathrm{~Hz}, 10 \mathrm{~min}, 85 \pm 4 \%$ of baseline, $n=6$; data not shown) or by three 1 min applications given at 2 min intervals ( $n=4 ; p>0.8$ when compared with a 10 min CCh application) (Fig. 1D), indicating that prolonged agonist application is not required.

To confirm that the CCh-induced LTD at CA3-CA1 synapses requires activation of $\mathrm{mAChRs}$ rather than nicotinic acetylcholine receptors (nAChRs), we used the nonselective mAChR antagonist atropine and the $\mathrm{nAChR}$ antagonist methyllycaconitine (MLA) (10 $\mu \mathrm{M}$, a concentration that will block all nicotinic receptor subtypes in hippocampus) (Alkondon and Albuquerque, 2004; Karadsheh et al., 2004) and found that the effects of CCh were unaffected by MLA $[n=6 ; p>0.6$ when comparing mLTD with $(n=6)$ and without $(n=6)$ MLA in interleaved experiments] (Fig. $1 E$ ) but were completely prevented by atropine (1 $\mu \mathrm{M} ; n=5 ; p>0.5$ when comparing baseline transmission to 40 min after CCh application) (Fig. $1 F$ ). Thus, we have termed this form of LTD muscarinic LTD. mLTD requires the activation of the $M_{1}$ subtype of mAChRs because it was almost completely prevented by the highly selective and irreversible $\mathrm{M}_{1}$ toxin $\mathrm{MTx}-7$ (Max et al., 1993a,b; Potter, 2001) [100 nM (Fig. $1 G) ; p<0.001$ when comparing mLTD with $(n=4)$ and without $(n=5)$ MTx-7 in interleaved experiments] and mLTD was blocked by the $\mathrm{mAChR}$ antagonist pirenzepine at a concentration selective for $\mathrm{M}_{1}$ receptors (75 nM) (Marino et al., 1998) $(n=5 ; p>0.5$ when comparing before and $40 \mathrm{~min}$ after $\mathrm{CCh}$ application in pirenzepine) (supplemental Fig. 1A, available at www.jneurosci.org as supplemental material). [Note that a higher concentration of pirenzepine $(10 \mu \mathrm{M})$, often used to determine the involvement of $\mathrm{M}_{1}$ receptors, not only blocks mLTD but also the transient depression during CCh application, demonstrating that this concentration is not selective for $\mathrm{M}_{1}$ receptors (supplemental Fig. $1 B$, available at www.jneurosci.org as supplemental material).] Using the selective $\mathrm{M}_{1}$ agonist $\mathrm{McN}-\mathrm{A}-343(\mathrm{McN}), \mathrm{mLTD}$ is induced at the same magnitude as with CCh $(50 \mu \mathrm{M} ; n=15 ; p>0.5$ when compared with mLTD 
induced with CCh) (Fig. $1 \mathrm{H})$. Even at a concentration as low as $1 \mu \mathrm{M} \mathrm{McN}$, in two of three slices recorded, mLTD was clearly induced ( $n=2 / 3$ slices) (C. L. Scheiderer, L. E. Dobrunz, and L. L. McMahon, unpublished observations). Collectively, these data provide strong support for a role of $\mathrm{M}_{1}$ receptors in mLTD induction. Finally, expression of mLTD is unaffected by $\mathrm{GABA}_{\mathrm{A}}$ receptor blockade with bicuculline $[10 \mu \mathrm{M} ; n=4 ; p>$ 0.05 when comparing mLTD with $(n=4)$ and without $(n=6)$ bicuculline] (Fig. $1 I)$, indicating that a CCh-induced increase in GABAergic inhibition (Pitler and Alger, 1992) is not the source of the mLTD.

mLTD expression is likely to be postsynaptic because there is no significant change in the paired-pulse facilitation $(\mathrm{PPF})$ ratio, a measure that gives indirect information about the presynaptic versus postsynaptic locus of a synaptic effect (Zucker, 1989; Dobrunz and Stevens, 1997), during mLTD expression compared with baseline when induced with either agonist (CCh, $n=7, p>0.05 ; \mathrm{McN}$, $n=6, p>0.05$ ) (supplemental Fig. $1 C-D$, available at www.jneurosci.org as supplemental material). However, a significant change in the PPF ratio does occur during CCh application (i.e., transient depression) but not during application of $\mathrm{McN}$ (CCh, $n=7, p<0.05 ; \mathrm{McN}, n=6, p>$ 0.05 ) (supplemental Fig. $1 C-D$, available at www.jneurosci.org as supplemental material). This suggests that $\mathrm{CCh}$ activates presynaptic mAChRs other than $M_{1}$ receptors to decrease release probability, which explains the larger depression during CCh application compared with $\mathrm{McN}$. The identity of the presynaptic mAChRs that mediate the presynaptic depression continues to be investigated, and probably more than one subtype is involved (Kremin et al., 2005; Shinoe et al., 2005). Consistent with previous work suggesting that the $\mathrm{M}_{3}$ subtype is partially involved (Auerbach and Segal, 1996), we find that the selective $\mathrm{M}_{3}$ antagonist 4-diphenylactoxy- $N$-methylpiperidine (4-DAMP) (Ehlert, 1996) decreases the CCh-induced transient depression (100 nM; $86 \pm$ $5 \%$ of baseline fEPSP slope during CCh application in 4-DAMP; $n=5$ vs $14 \pm 7 \%$ of baseline fEPSP slope in CCh application alone; $p<0.05$; data not shown). However, as expected for a $\mathrm{M}_{3}$ antagonist, 4-DAMP has no effect on the magnitude of mLTD ( $82 \pm 4 \%$ of baseline fEPSP in 4-DAMP; $n=5 ; p>0.05$ vs CCh alone; data not shown). This finding indicates that the presynaptic depression and mLTD are separate mechanisms and, moreover, that the presynaptic depression is not required for mLTD induction because the magnitude of mLTD is the same regardless of whether it is induced with $\mathrm{McN}$ (which activates $\mathrm{M}_{1}$ receptors primarily) or with $\mathrm{CCh}$ (which will activate all mAChRs). Because the focus of this study is mLTD, complete pharmacological characterization of the presynaptic depression was not pursued further.

We next determined whether mLTD requires concurrent presynaptic activity and postsynaptic activation of the NMDA sub-
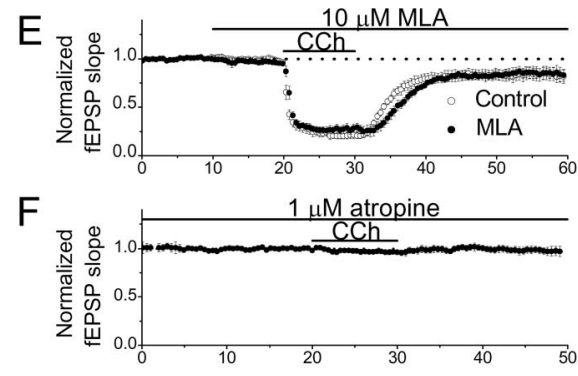

$\mathrm{G}$
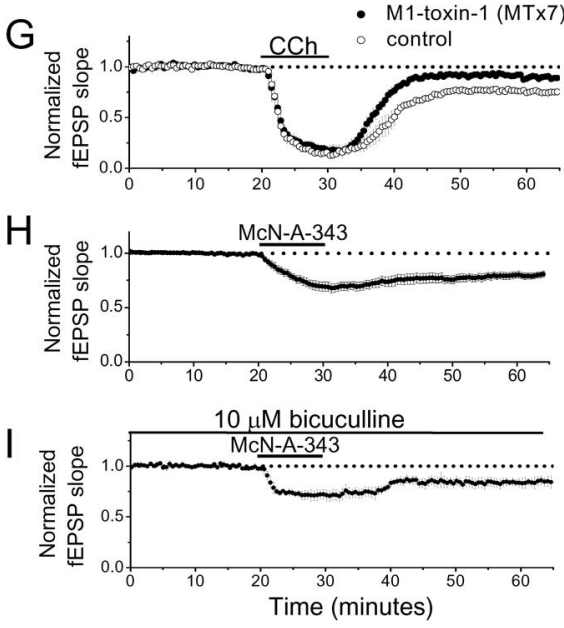

Figure 1. Activation of $\mathrm{M}_{1}$ muscarinic acetylcholine receptors induces $\mathrm{mLTD}$. A, Average of 20 consecutive fEPSPs from 2 min before, during, and $30 \mathrm{~min}$ after $50 \mu \mathrm{m}$ CCh application. Calibration: $0.5 \mathrm{mV}, 10 \mathrm{~ms}$. Traces were obtained from the experiment B. B, A single experiment demonstrating C Ch-induced transient depression and $\mathrm{mLTD}$ after CCh washout. C, Summary of of baseline, $n=6, p>0.8 \mathrm{vs} \mathrm{mLTD} \mathrm{induced} \mathrm{with} \mathrm{the} 10 \mathrm{~min}$ application). $\boldsymbol{E}$, mLTD is not altered by $10 \mu \mathrm{m} \mathrm{MLA}$, a nicotinic 列 $n=5$ without toxin, $p<0.001)$. $\boldsymbol{H}$, The selective $\mathrm{M}_{1}$ receptor agonist $\mathrm{McN}-\mathrm{A}-343(50 \mu \mathrm{m})$ elicits $\mathrm{mLTD}$ of the same magnitude as CCh (77 $\pm 1 \%$ of baseline during $\mathrm{mLTD}, n=15, p>0.5)$. $I$, The $\mathrm{GABA}_{\mathrm{A}}$ receptor antagonist bicuculline $(10 \mu \mathrm{m})$ does not affect $\mathrm{mLTD}$ ( $84 \pm 4 \%$ of baseline fEPSP slope in bicuculline, $n=4, p>0.05$ vs McN alone).

type of glutamate receptor (NMDAR). We find that mLTD is NMDAR-dependent, because it is blocked in the presence of the NMDAR antagonist D,L-2-amino-5-phosphopentanoic acid (D,L-APV) $(100 \mu \mathrm{M} ; n=5 ; p>0.5)$ (Fig. $2 A, B)$. Furthermore, mLTD requires presynaptic activity, because interruption of stimulation during CCh application prevents induction of the plasticity in that pathway when CA3 cell bodies are removed from the slice (Fig. 2D) ( $n=6 ; p<0.05$ between pathways). Removal of CA3 cell bodies was necessary to reveal the activity dependence because $\mathrm{CCh}$ induces theta-like rhythmic oscillations in these cells (Williams and Kauer, 1997). These oscillations produce activity at CA3-CA1 synapses even in the absence of electrical stimulation, masking the activity dependence of mLTD (Fig. $2 C)(n=$ $8 ; p>0.1$ between pathways). Together, these data demonstrate that mLTD is both an activity- and NMDAR-dependent form of synaptic plasticity similar to other forms of hippocampal plasticity believed to be important for learning and memory, thus strengthening the idea that mLTD could participate in memory formation.

\section{Sympathetic sprouting rescues mLTD after cholinergic denervation}

To investigate whether mLTD expression is affected by cholinergic denervation and hippocampal sympathetic ingrowth from 


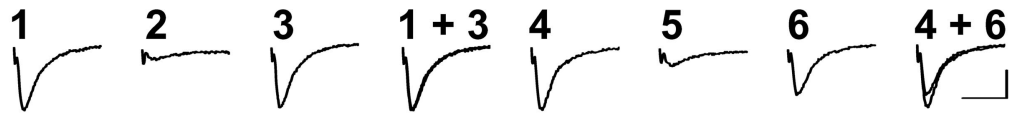

A

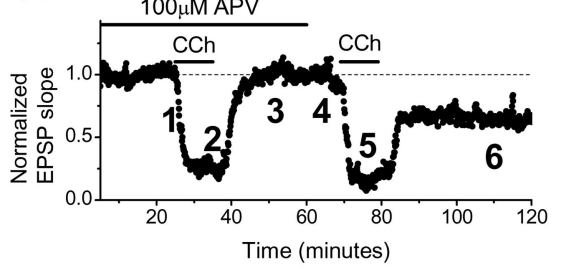

C

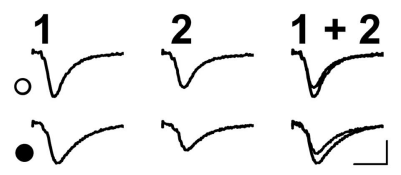

intact slice

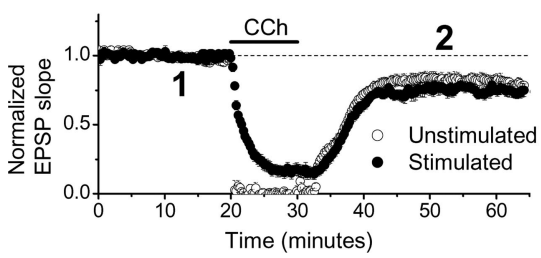

B

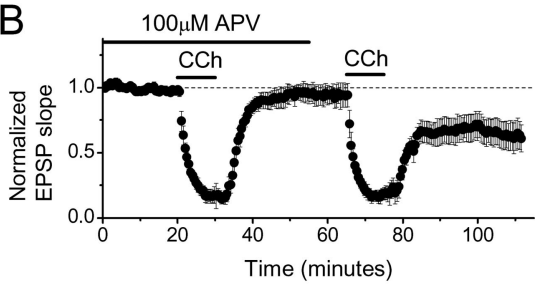

D

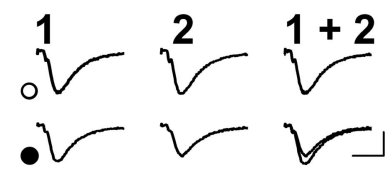

CA3 removed

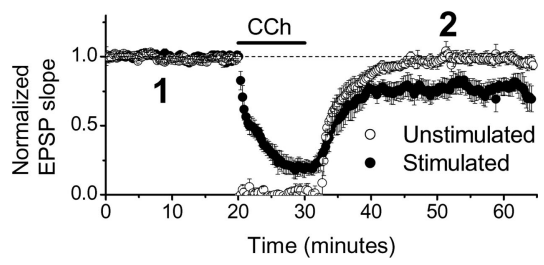

Figure 2. $\quad \mathrm{mLTD}$ is NMDAR- and activity-dependent. $\boldsymbol{A}$, Single example and summary $(\boldsymbol{B})$ of NMDAR dependence of $\mathrm{mLTD}$. The NMDAR antagonist D,L-APV $(100 \mu \mathrm{M})$ prevents $\mathrm{mLTD}$, whereas CCh reapplication to the same slice after $\mathrm{D}, \mathrm{L}-\mathrm{APV}$ washout elicits $\operatorname{mLTD}(95 \pm 7$ of baseline in $\mathrm{D}, \mathrm{L}-\mathrm{APV}, n=5 ; 72 \pm 5 \%$ of baseline without APV,$n=6 ; p<0.05 \pm \mathrm{D}, \mathrm{L}-\mathrm{APV}$ ). Averaged traces shown are from the experiment in $\boldsymbol{A}$. $\boldsymbol{C}$, Stimulation of two independent pathways in intact slices $(82 \pm 5 \%$ of baseline in stimulated path vs $77 \pm 5 \%$ of baseline in unstimulated path, $n=8, p>0.05$ between pathways) and in slices with (A3 cell bodies removed $(\boldsymbol{D} ; 78 \pm 6 \%$ of baseline in stimulated path vs $99 \pm 2 \%$ of baseline in unstimulated path, $n=6, p<0.05$ between pathways) demonstrates that mLTD is activity dependent. During (Ch application, stimulation to one pathway is ceased (unstimulated), whereas the other remains active (stimulated). All representative traces are averages of 20 waveforms from the time points indicated by the numbers. Calibration: $0.5 \mathrm{mV}, 10 \mathrm{~ms}$.

the SCG, we compared the amount of LTD induced in slices from animals with medial septal lesion with and without bilateral ganglionectomy. The first group of animals underwent surgery, but no lesions were made (sham group). The second animal group underwent medial septal lesion, either electrolytically or chemically with 192 IgG-saporin (see Materials and Methods), to cholinergically denervate hippocampus, and bilateral ganglionectomy to prevent adrenergic sympathetic ingrowth. This animal group allows the effect(s) of pure cholinergic denervation on mLTD to be assessed in the absence of potentially compensating effects of ingrowth on mAChR function and synaptic properties. The third group of animals underwent medial septal lesion (electrolytically or chemically), but the superior cervical ganglia were left in place to allow for ingrowth to occur. In addition, a separate group of animals underwent ganglionectomy alone; because data from these animals were not different from sham lesions, these data were pooled. Experiments were conducted at 4 weeks after electrolytic lesion or 12 weeks after 192 IgG-saporin lesion, when sympathetic ingrowth is well established (Loy and Moore, 1977; Crutcher et al., 1981; Crutcher, 1987; Harrell et al., 2001). Completeness of lesions was confirmed in all animals and data were discarded if the lesion was incomplete (see Materials and Methods and supplemental Fig. 2 for examples of lesion confirmation). Because the data from animals with electrolytic and immunotoxin lesions were not significantly different, these data were pooled. However, the data separated by lesion method are presented in supplemental Figure 3.
First, we confirmed that mLTD can be induced in slices from sham animals (Fig. $3 A)(n=11$ slices $/ 5$ sham animals, $p<$ 0.05 ; data from electrolytic and immunotoxin sham lesions were not significantly different, $p>0.1$ ). We found that the amount of mLTD induced in sham animals is not different from that observed in 3 - to 4-week-old control animals $(p>$ 0.2 ), eliminating potential concerns regarding age-dependent effects on induction or expression of mLTD. Subsequently, we show that mLTD expression is completely absent in slices from animals with cholinergic denervation combined with bilateral ganglionectomy to prevent sympathetic ingrowth from the SCG into hippocampus (Fig. $3 B)(n=10$ slices $/ 5$ animals with bilateral ganglionectomy, $p<$ 0.001 when compared with sham; data from electrolytic and immunotoxin lesions were not significantly different, $p>0.4$ ). This finding clearly demonstrates that intact cholinergic innervation of hippocampus from medial septum is required for mLTD expression. Surprisingly, mLTD expression is at control levels in slices from animals with cholinergic denervation and intact SCG to allow sympathetic ingrowth to occur (Fig. $3 C)(n=16$ slices $/ 9$ animals with intact ganglia, $p>0.9$ when compared with sham lesion; data from electrolytic and immunotoxin lesions were not significantly different, $p>0.9)$. It is important to note that the presynaptic depression is not altered between the three groups $(p>0.5)$, indicating that cholinergic denervation causes a selective deficit in $\mathrm{M}_{1}$ receptormediated effects on synaptic function, not a global deficit in muscarinic receptor signaling. Collectively, our findings reveal a novel mechanism whereby sympathetic ingrowth modulates synaptic transmission, rescues mLTD, and functionally compensates for loss of hippocampal cholinergic innervation.

\section{Loss of plasticity is specific for mLTD}

Next, we tested whether the loss of mLTD after cholinergic denervation is specific for this form of plasticity. First, LTP induced by high-frequency stimulation $(100 \mathrm{~Hz}$ tetanus, $1 \mathrm{~s}$ duration, repeated twice) reaches the same magnitude in all animal groups, indicating that cholinergic denervation and sympathetic ingrowth do not alter this form of plasticity (Fig. $4 A)(n=4$ sham lesion, $n=4$ with intact ganglia to allow ingrowth, $n=5$ with bilateral ganglionectomy to prevent ingrowth; $p>0.6$ between groups). Subsequently, we find that LTD induced by LFS $(1 \mathrm{~Hz}$, $15 \mathrm{~min}$ ) is unaffected by cholinergic denervation and bilateral ganglionectomy to prevent ingrowth (Fig. $4 B)(n=6$ slices $/ 3$ sham lesioned animals and $n=7$ slices/ 3 animals with bilateral ganglionectomy to prevent ingrowth; $p>0.8$ between groups). Even within the same slice in which MLTD cannot be induced, LFS-LTD can be readily elicited, clearly documenting specific loss of mLTD (Fig. $4 C)(n=5$ slices $/ 3$ animals with bilateral ganglionectomy to prevent ingrowth; depression after CCh, $p>$ 0.1 ; depression after LFS, $p<0.05)$. Moreover, NE LTD, a form of LTD induced by activation of $\alpha 1$ adrenergic receptors 
(Scheiderer et al., 2004), is not different between groups, although this plasticity shares mechanistic properties with mLTD (100 $\mu \mathrm{M}$ phenylephrine; $n=8$ slices $/ 3$ sham lesioned animals, $n=4$ slices $/ 3$ animals with intact ganglia to allow ingrowth, $n=6$ slices $/ 3$ animals with bilateral ganglionectomy to prevent ingrowth; $p>0.5$ between groups) (Fig. 4D). Because ACh and NE can modulate one another's release in hippocampus (Nilsson et al., 1992; Kiss et al., 1999), it is important to note that MLTD and NE LTD are separate plasticities, because mLTD is not affected by the $\alpha 1$ antagonist prazosin $(10 \mu \mathrm{M})$, and NE LTD is unaffected by the mAChR antagonist atropine $(1 \mu \mathrm{M}$; C. L. Scheiderer, L. E. Dobrunz, L. L. McMahon, unpublished observations). Because NE LTD expression is normal, and $\alpha 1$ adrenergic and $\mathrm{M}_{1}$ muscarinic receptors both couple through Gq, the loss of mLTD after cholinergic denervation in the absence of ingrowth cannot be explained by a general deficit in G-protein-associated processes. Together, these findings reemphasize that the structural rearrangements induced by medial septal lesion specifically affect mLTD.

\section{Increased cholinergic innervation is seen in animals with \\ sympathetic ingrowth}

Our data demonstrate preservation of a cholinergic-dependent synaptic plasticity in hippocampus when adrenergic ingrowth of fibers from the SCG is stimulated by loss of central cholinergic innervation. How sympathetic fibers with an adrenergic phenotype restore cholinergic function in hippocampus is unknown. A small percentage $(<1 \%)$ of SCG neurons are cholinergic (Schafer et al., 1998), and sympathetic neurons, including those in the SCG, are capable of gaining a cholinergic phenotype or switching their phenotype altogether from adrenergic to cholinergic (Furshpan et al., 1976; Potter et al., 1981; Landis and Keefe, 1983; Wolinsky and Patterson, 1983; Schafer et al., 1997, 1998; Francis and Landis, 1999; Yang et al., 2002; Weihe et al., 2005). Therefore, we entertained the possibility that sprouting from the SCG might restore cholinergic function, and thus mLTD expression, by replacing lost central cholinergic innervation to hippocampus, potentially by any one, or all, of these mechanisms. Thus, if the prediction is correct, axons immunopositive for a marker of cholinergic terminals should accompany adrenergic sympathetic ingrowth, and accordingly, bilateral ganglionectomy should prevent appearance of these potential cholinergic fibers.
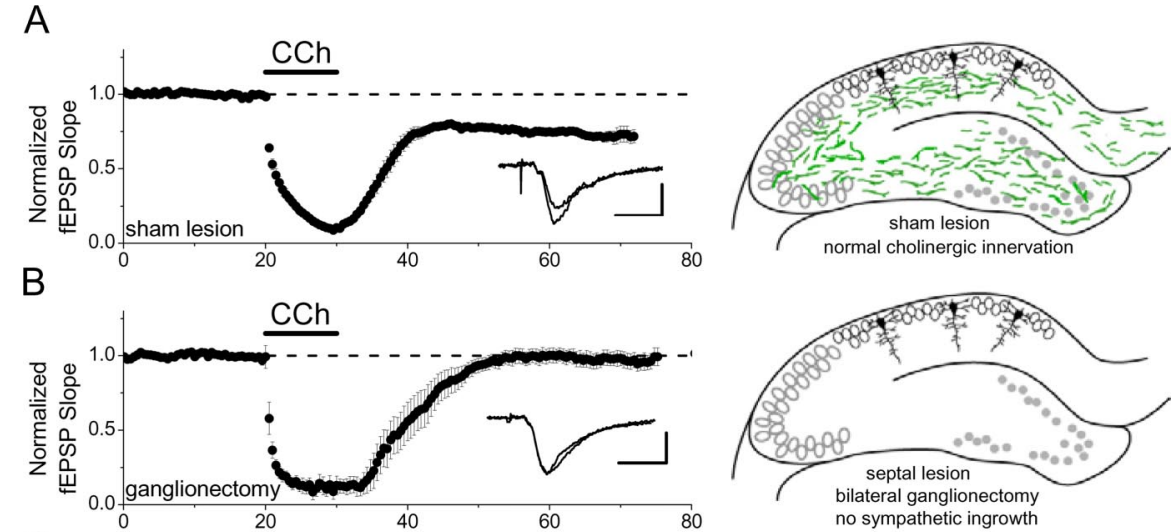

C
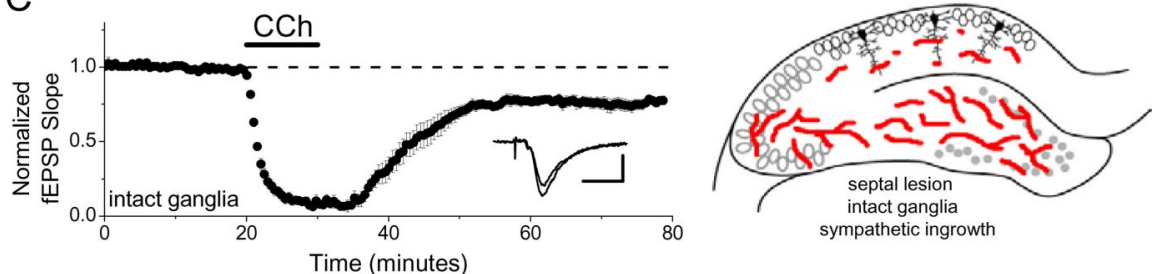

Figure 3. $m L T D$ is lost in cholinergically denervated animals but is restored by sympathetic ingrowth. $\boldsymbol{A}, \mathrm{mLTD}$ in slices from sham animals ( $p>0.1$ when comparing lesion methods; therefore, data are pooled, $78 \pm 2 \%$ of baseline, $n=11$ slices $/ 6$ animals, $p<0.05$; sham electrolytic lesions, $77 \pm 2 \%$ of baseline, $n=6$ slices/3 animals; sham $192 \mathrm{lgG}$-saporin lesions, $82 \pm$ $3 \%$ of baseline, $n=5$ slices/ 3 animals). [Note: data separated by lesion method are shown in supplemental Figure 3.] Illustration on the right demonstrates the normal pattern of hippocampal cholinergic innervation (green). $\boldsymbol{B}, \mathrm{mLTD}$ is lost in slices from animals with medial septal lesion and bilateral superior cervical ganglionectomy to prevent sympathetic ingrowth ( $97 \pm 3 \%$ of baseline, $n=10$ slices/5 animals) ( $p>0.4$ when comparing lesion methods; therefore, data are pooled; electrolytic lesions, $99 \pm 3 \%$ of baseline, $n=7$ slices/ 3 animals; $192 \mathrm{lgG}$-saporin lesions, $95 \pm 2 \%$ of baseline, $n=3$ slices/ 2 animals). Illustration on the right demonstrates the lack of septal cholinergic innervation in hippocampal slices from these animals and no ingrowth of sympathetic fibers attributable to bilateral ganglionectomy. $C, \mathrm{mLTD}$ is at control levels in animals with medial septal lesion when the SCG are left intact to allow ingrowth to occur ( $78 \pm 3 \%$ of baseline, $n=16$ slices $/ 9$ animals) ( $p>0.9$ when comparing lesion methods, therefore data are pooled; electrolytic lesions, $79 \pm 3 \%$ of baseline, $n=9$ slices $/ 5$ animals; 192 lgG-saporin lesions, $79 \pm 5 \%$ of baseline, $n=7$ slices/4 animals). The illustration on the right shows the absence of cholinergic innervation attributable to medial septal lesion and the pattern of sympathetic ingrowth (red) when the ganglia remain intact. Calibration: $0.5 \mathrm{mV}$, $10 \mathrm{~ms}$.
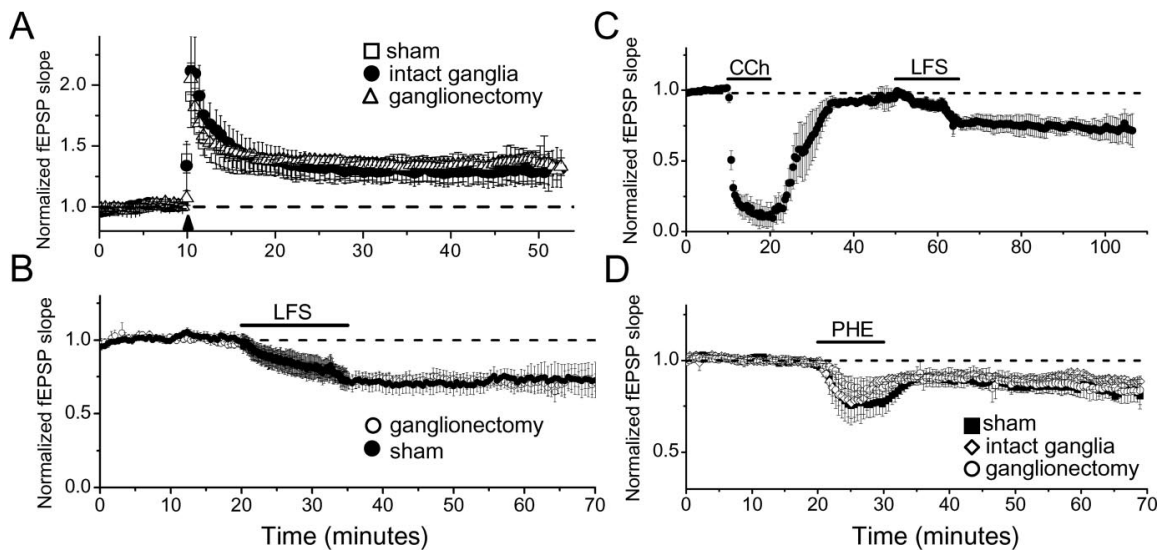

Figure 4. Loss of plasticity is specific for mLTD. $A$, HFS-induced LTP is unaffected by cholinergic denervation with and without bilateral ganglionectomy ( $131 \pm 11 \%$ of baseline, $n=5$ slices $/ 4$ sham animals; $133 \pm 12 \%$ of baseline, $n=5$ slices $/ 4$ animals with intact ganglia to allow ingrowth; $138 \pm 5 \%$ of baseline, $n=9$ slices $/ 5$ animals with bilateral ganglionectomy to prevent ingrowth). $\boldsymbol{B}$, LFS-LTD in slices from animals with bilateral ganglionectomy to prevent ingrowth is not different from the magnitude of LFS-LTD induced in slices from sham lesioned animals ( $70 \pm 6 \%$ of baseline, $n=7$ slices/3 animals with bilateral ganglionectomy vs $72 \pm 7 \%$ of baseline, $n=6$ slices $/ 3$ sham lesioned animals). $\boldsymbol{C}$, mLTD expression is absent but LFS-LTD expression is normal in slices from animals with bilateral ganglionectomy to prevent ingrowth $(93 \pm 5 \%$ of baseline after CCh application vs $74 \pm 6 \%$ of baseline after LFS, $n=5$ slices/3 animals with bilateral ganglionectomy to prevent ingrowth). D, LTD induced by activation of $\alpha 1$ adrenergic receptors (NE LTD) by $100 \mu \mathrm{m}$ phenylephrine is not altered in cholinergic denervated animals with or without bilateral ganglionectomy ( $85 \pm 3 \%$ of baseline, $n=8$ slices $/ 3$ animals with sham lesions; $89 \pm 2 \%$ of baseline, $n=4$ slices $/ 3$ animals with bilateral ganglionectomy to prevent ingrowth; $87 \pm 4 \%$ of baseline, $n=6$ slices $/ 3$ animals with intact ganglia to allow ingrowth). 

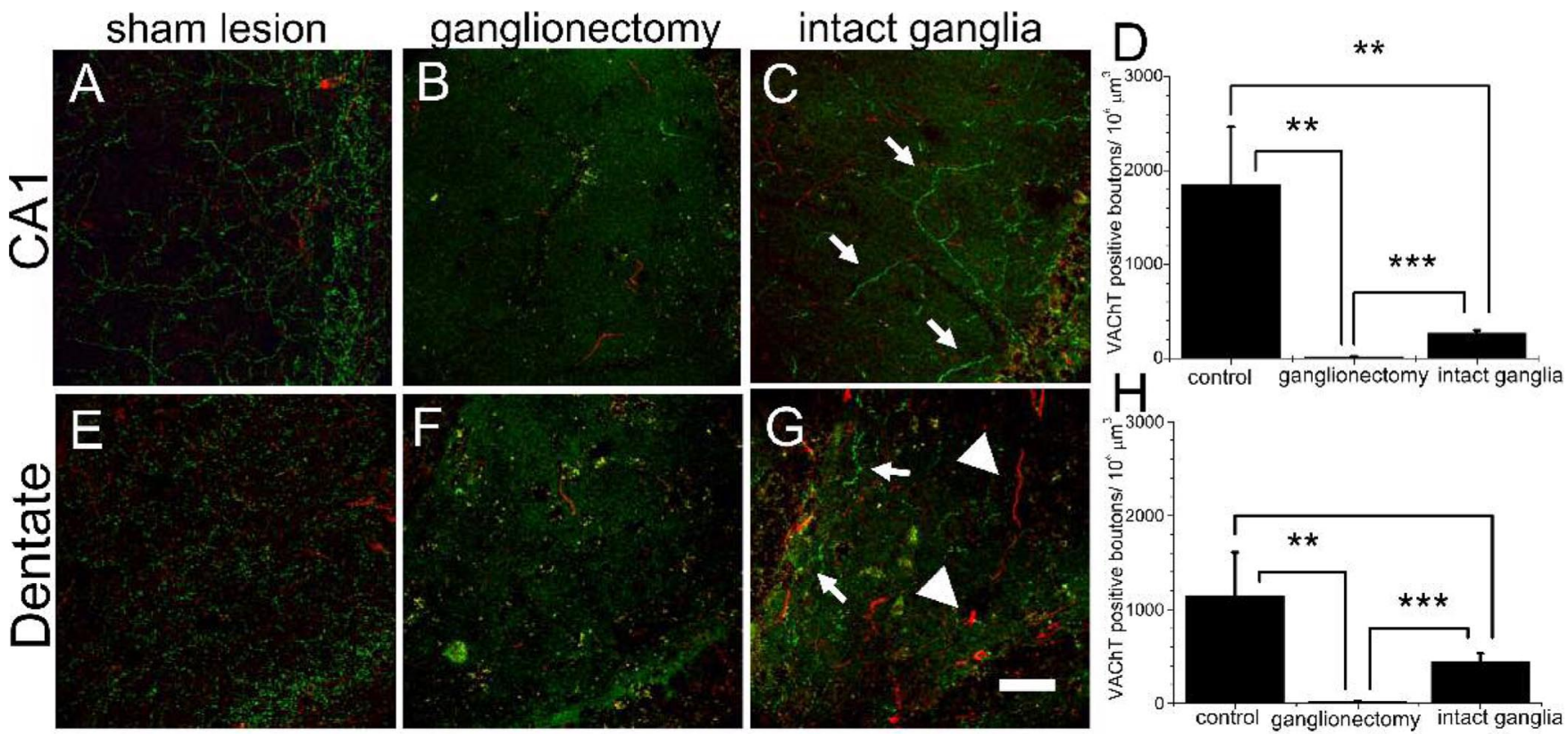

Figure 5. VAChT-positive boutons are increased in hippocampus and dentate gyrus only when SCG are left intact to permit adrenergic sympathetic ingrowth. Noradrenergic fibers (originating from both locus ceruleus and superior cervical ganglia) were identified using an antibody directed at $\mathrm{TH}$; cholinergic fibers were identified using an antibody directed at VAChT. Analysis of sections stained for TH (red) and VAChT (green) show that there are more VAChT-positive boutons ( $C, G$, arrows) in CA1 and dentate gyrus in slices from animals with intact SCG to allow adrenergic ingrowth compared with slices from animals with bilateral ganglionectomy to prevent adrenergic ingrowth (A-C; VAChT-positive boutons in CA1: $267 \pm 32$ boutons in animals with intact ganglia to allow ingrowth, $n=6$ animals vs $29 \pm 8$ boutons in animals with bilateral ganglionectomy to prevent ingrowth, $n=9$ animals; $\boldsymbol{E}-\boldsymbol{G}$; VAChT-positive boutons in dentate gyrus: $442 \pm 88$ boutons in animals with intact ganglia to allow ingrowth, $n=6$ animals vs $19 \pm 4$ boutons in animals with bilateral ganglionectomy to prevent ingrowth, $n=9$ animals). VAChT-positive boutons were counted in a blind manner, with the criterion that at least four consecutive boutons must be observed to be classified as a fragment of axon and be counted. Bar charts demonstrate significantly more VAChT-positive boutons in CA1 (D) and dentate gyrus $(\boldsymbol{H})$ of animals with intact ganglia than those with bilateral ganglionectomy. $\boldsymbol{G}$, Note the thick, TH-positive fibers indicative of adrenergic sympathetic ingrowth in dentate gyrus (arrowheads, red stained fibers) when SCG are left intact. At least three sections per animal were imaged and the number of boutons counted was averaged. Scale bar, $40 \mu \mathrm{m} .{ }^{* *} p<0.001 ;{ }^{* * *} p<0.0001$.

We tested this idea using double-immunofluorescent histochemistry in hippocampal slices to label cholinergic and adrenergic fibers using antibodies against VAChT, the marker used most often to identify cholinergic terminals (Schafer et al., 1998; Wong et al., 1999; Ferguson et al., 2003; Hu et al., 2003; Weihe et al., 2005) and TH, respectively. The presence of double labeling in single fibers would be indicative of a gain in cholinergic phenotype (Weihe et al., 2005). As in previous experiments, completeness of medial septal lesions was confirmed in all animals, and data were discarded if the lesion was incomplete (see Materials and Methods). To confirm the presence of adrenergic ingrowth, dentate gyrus was examined for the presence of thick, THpositive fibers indicative of ingrowth because sympathetic sprouting is most dense in this area (Loy and Moore, 1977; Stenevi and Bjorklund, 1978; Crutcher et al., 1981). We found these characteristic fibers in dentate gyrus and area CA3 (and rarely in area CA1) of slices from animals with intact ganglia (Fig. 5G) consistent with previous reports (Loy and Moore, 1977; Stenevi and Bjorklund, 1978; Crutcher et al., 1981) but not in slices from sham lesioned animals (Fig. $5 E$ ) or from lesioned animals with bilateral ganglionectomy to prevent ingrowth (Fig. $5 F$ ).

We found virtually no VAChT-positive fibers in either CA1 or dentate gyrus in slices from animals with medial septal lesion and SCG bilaterally removed to prevent ingrowth, demonstrating that the medial septal lesions were complete (Fig. 5B, F) (CA1: $1.0 \pm 0.3 \%$ of control; dentate gyrus: $1.7 \pm 0.4 \%$ of control; $n=$ 9 animals; $p<0.0001$ compared with sham lesion). In support of our hypothesis, in slices from animals with intact ganglia to permit sympathetic ingrowth, we found a striking number of VAChT-positive fibers with obvious boutons in area CA1 (Fig.
5C) $(14 \pm 2 \%$ of control; $n=6$ animals with intact ganglia, $n=$ 9 animals with bilateral ganglionectomy; $p<0.0001$ comparing \pm bilateral ganglionectomy), suggesting the possibility that new cholinergic fibers are present in hippocampus. These VAChT-positive fibers are also present in dentate gyrus, as would be expected if sprouting from the SCG is responsible (Fig. $5 E-H$ ) (38 $\pm 8 \%$ of control; $n=6$ animals with intact ganglia, $n=9$ with bilateral ganglionectomy; $p<0.0001$ comparing \pm bilateral ganglionectomy). We did not see colocalization of VAChT and TH within single fibers, indicating that the VAChT-positive fibers are not a result of a gain of cholinergic phenotype by adrenergic SCG neurons. However, this does not rule out a potential switch from adrenergic to cholinergic phenotype that has occurred before the 4 week time point.

\section{Cholinergic reinnervation temporally correlates with the rescue of $\mathrm{mLTD}$}

If the sprouted VAChT-positive fibers are directly responsible for the rescue of $\mathrm{MLTD}$, the time course of their appearance and the reestablishment of mLTD expression should directly overlap. To test this prediction, we did a time course study using electrolytic lesions, because this method provides more defined timing of cholinergic cell death. We first examined $3 \mathrm{~d}$ after electrolytic medial septal lesion, a point when cholinergic degeneration is still occurring and before ingrowth begins (Crutcher, 1987). Consistent with this, the number of VAChT positive boutons, although decreased, still remains $>30 \%$ of control levels in area CA1 in animals with medial septal lesion with and without bilateral ganglionectomy, indicating that the degeneration is not yet complete (Figs. $6 A-C, 7$ ) [36 $\pm 15 \%$ of control in slices from lesioned 
animals with bilateral ganglionectomy $(n=4)$ and $32 \pm 12 \%$ of control in slices from lesioned animals with intact ganglia $(n=4) ; p>0.5$ between groups]. In addition, at this time mLTD expression is intact in slices from all three animal groups (Fig. $6 D)$ ( $p>0.05$ between groups). This indicates that the cholinergic innervation that remains is still enough to support mLTD induction and therefore that $\mathrm{M}_{1}-\mathrm{Gq}$ coupling is still intact.

Subsequently, we examined $10 \mathrm{~d}$ after medial septal lesion, a point at which central cholinergic afferents have degenerated and at which ingrowth is beginning to be established in animals with intact ganglia (Crutcher, 1987). VAChT staining at this time point shows that the density of cholinergic boutons in slices from lesioned animals with bilateral ganglionectomy (to prevent ingrowth) is down to only $1 \pm 1 \%$ of the control level seen in sham lesioned animals (Figs. $6 E-G, 7)(n=5$ animals with ganglionectomy to prevent ingrowth; $p<0.001$ when compared with sham lesioned animals). mLTD expression is now absent (Fig. $6 H)(n=10$ slices/5 animals with bilateral ganglionectomy; $p<0.01$ when compared with sham lesioned animals). In sharp contrast, VAChT staining shows that the density of cholinergic boutons has increased from $1 \%$ of control in lesioned animals with ganglionectomy to $15 \pm 1 \%$ of control in slices from lesioned animals with intact ganglia and ingrowth, (Figs. $6 F, G, 7)(n=6$ animals with intact ganglia; $p<0.01$ when comparing with or without bilateral ganglionectomy). Importantly, mLTD is clearly present in slices from these animals (Fig. $6 H)(n=10$ slices/5 animals with intact ganglia; $p<0.01$ ). Even at this early time point, we did not observe fibers double labeled for VAChT and TH. Together, these data show that both mLTD expression and VAChT staining are lost within $10 \mathrm{~d}$ of medial septal lesion with bilateral ganglionectomy, and that, in animals with intact ganglia and ingrowth, the rescue of mLTD occurs coincidentally with the SCG-dependent appearance of VAChT-positive fibers in hippocampus.

\section{Unilateral ganglionectomy removes} cholinergic reinnervation only from the ipsilateral side

Our data clearly indicate that the SCG is required for the reappearance of VAChTpositive fibers in CA1 after medial septal lesion. Subsequently, we reasoned that, if the VAChT-positive fibers originate from the SCG, removing one ganglion unilaterally at a time when sprouting is well established should cause these fibers to rapidly disappear on the ipsilateral side. To test this idea, unilateral gan-

\section{3 days post lesion}
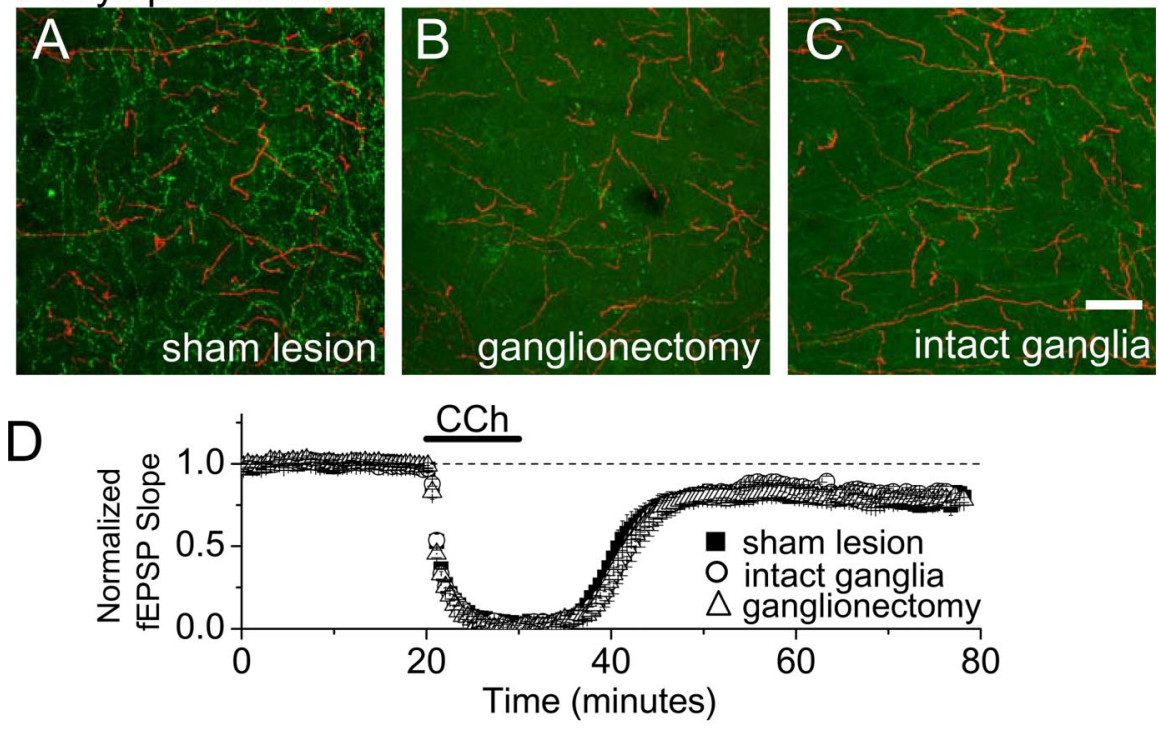

\section{0 days post lesion}
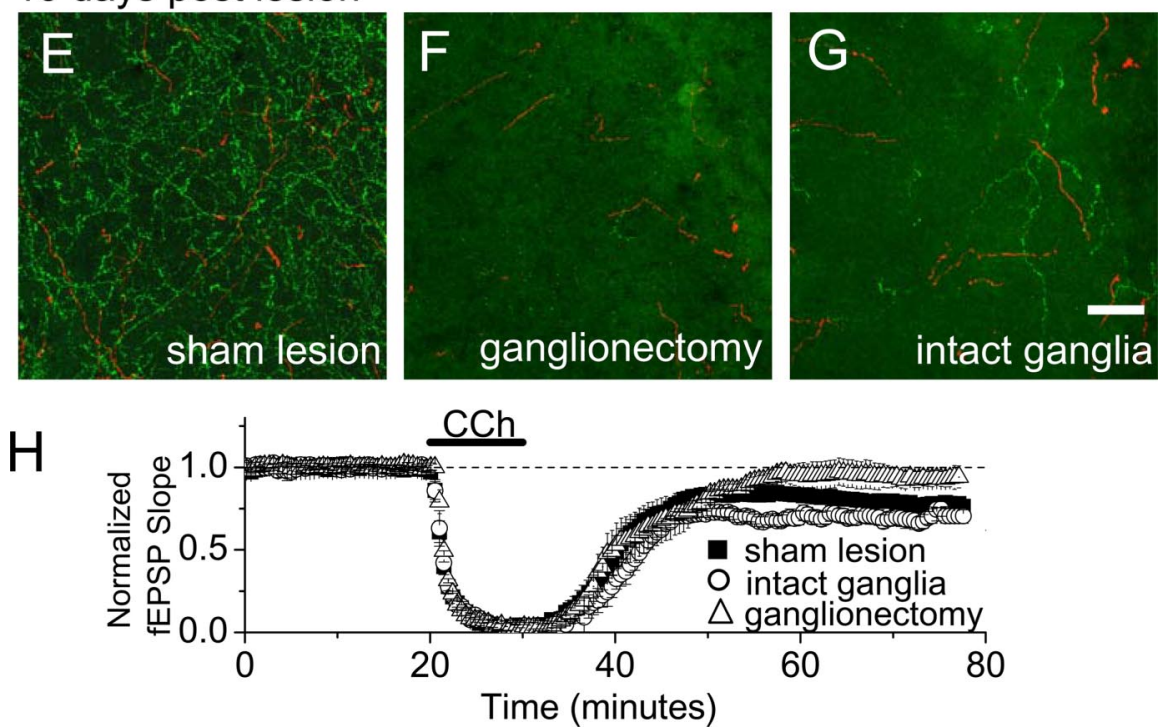

Figure 6. Cholinergic reinnervation is temporally correlated with the rescue of $\mathrm{mLTD}$ expression. $\boldsymbol{A}-\boldsymbol{C}$, Three days after electrolytic lesion: immunohistochemical staining demonstrates VAChT (green) and TH (red) distribution in area CA1 in sham lesioned animals ( $n=4$ animals), animals with intact ganglia (ingrowth possible, $n=4$ animals), and animals with bilateral ganglionectomy (no ingrowth possible, $n=4$ animals). VAChT-positive boutons are decreased relative to control $(\boldsymbol{A})$ in animals with ganglionectomy ( $\boldsymbol{B}$; no ingrowth possible; $766 \pm 333$ boutons, $n=3$ animals) and with intact ganglia ( $\boldsymbol{C}$; ingrowth possible; $684 \pm 275$ boutons, $n=3$ animals). Note (in $C$ ) that because adrenergic ingrowth does not appear (in animals with intact ganglia) until at least $7 \mathrm{~d}$ after medial septal lesion, no thick TH-positive fibers are observed. $\boldsymbol{D}, \mathrm{mLTD}$ can be induced in slices from animals in all experimental groups at $3 \mathrm{~d}$ after medial septal lesion with or without ganglionectomy [ $76 \pm 3 \%$ of baseline, $n=$ 9 slices/ 4 animals with sham lesion; $80 \pm 3 \%$ of baseline, $n=9$ slices/4 animals with ganglionectomy (no possible ingrowth); $78 \pm 2 \%$ of baseline, $n=11$ slices/4 animals with intact ganglia (ingrowth possible)]. $\boldsymbol{E}-\boldsymbol{G}$, Ten days after electrolytic lesion, immunohistochemical staining shows that the number of VAChT-positive boutons is significantly reduced in slices from animals with ganglionectomy (no ingrowth possible; $\boldsymbol{F} ; 73 \pm 20$ boutons, $n=5$ animals) compared with those with intact ganglia (ingrowth possible; $\boldsymbol{G} ; 351 \pm 86$ boutons, $n=6$ animals). $\boldsymbol{H}$, At $10 \mathrm{~d}$ after lesion, mLTD can be induced in slices from sham lesioned animals ( $79 \pm 3 \%$ of baseline, $n=14$ slices/ 5 animals) and in animals with intact ganglia (ingrowth possible; $70 \pm 4 \%$ of baseline, $n=10$ slices $/ 5$ animals) but not in slices from animals with ganglionectomy (no possible ingrowth; $96 \pm 8 \%$ of baseline slope, $n=10$ slices $/ 5$ animals). At least three sections per animal were imaged, and the number of boutons counted from the imaged sections were averaged. Scale bar, $40 \mu \mathrm{m}$.

glionectomies were performed 4 weeks after electrolytic medial septal lesion, and VAChT staining was performed on ipsilateral and contralateral hippocampal sections obtained from animals killed 5-7 d after ganglion removal. Confirming our prediction, virtually no VAChT-positive boutons were found in slices from 


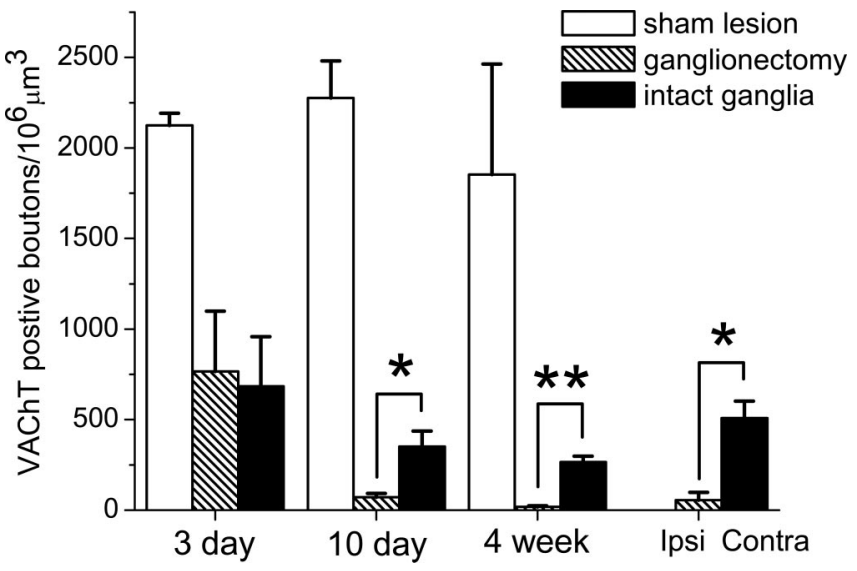

Figure 7. Time-dependent alterations in the number of VAChT-positive boutons after cholinergic denervation. Control VAChT staining is not significantly different in sham lesioned animals at the different time points. The number of VAChT-positive boutons continually decreases with time in slices from animals with ganglionectomy (no ingrowth possible), but this temporal decrease is not seen in slices from animals with intact ganglia (ingrowth possible). Unilateral ganglionectomy, performed 4 weeks after medial septal lesion when cholinergic reinnervation is well established, removes the VAChT-positive boutons from the ipsilateral side, whereas the cholinergic reinnervation on the contralateral side remains intact, indicating that the cholinergic reinnervation comes from the superior cervical ganglia $(56 \pm 42$ boutons ipsilateral vs $508 \pm 95$ boutons contralateral, $n=4$ animals). Animals were killed $5-7 \mathrm{~d}$ after the unilateral ganglionectomy. At least three sections per animal were imaged, and the number of boutons counted from the imaged sections were averaged. Asterisks indicate significance from animals without adrenergic ingrowth (ganglionectomy). ${ }^{*} p<0.01$; ${ }^{* *} p<0.001$.

the ipsilateral hippocampus after unilateral ganglionectomy. In fact, the number of VAChT-positive boutons was decreased by $89 \pm 8 \%$ on the ipsilateral side compared with the contralateral side (Fig. 7 , far right) $(n=4$ animals; $p<0.001)$. These data indicate that not only is the SCG responsible for the appearance of the VAChT-positive fibers, it appears to be the source of these fibers.

\section{Discussion}

We report the novel finding that a cholinergic-dependent LTD with Hebbian properties at hippocampal CA3-CA1 synapses is preserved, despite central cholinergic cell loss after medial septum lesion, by sprouting of sympathetic fibers originating from the SCG. The sympathetic sprouting stimulates an unexpected cholinergic reinnervation (new VAChT-positive fibers) of hippocampus, the appearance of which is tightly coupled temporally with the rescue of the $\mathrm{M}_{1} \mathrm{mAChR}$-dependent LTD. Intact SCG are required for both the appearance of VAChT-positive fibers and the mLTD rescue because these fibers and MLTD expression are absent in slices from animals with bilateral superior cervical ganglionectomy. This novel mechanism is a striking demonstration of direct interaction between the autonomic nervous system and the CNS, the consequence of which is the preservation of a cholinergic-dependent LTD at a set of central synapses known to be critical for normal learning and memory. This reinstatement of cholinergic innervation in hippocampus by the autonomic nervous system is a unique example of an attempt by the nervous system to maintain homeostasis in the face of neurodegeneration so that normal synaptic function can continue.

\section{Source of the VAChT-positive fibers}

Although the SCG is absolutely required for the cholinergic reinnervation to occur, the exact origin of the VAChT-positive fibers in hippocampus is not known. However, the rapid loss of these fibers, which occurs within 5-7 d after unilateral ganglionectomy performed at a time when reinnervation is well established, strongly suggests that the SCG is directly responsible for, and likely the source of, the cholinergic reinnervation. Sympathetic neurons, including those in the SCG, have the unique ability to gain a cholinergic phenotype and/or functionally alter their phenotype from adrenergic to cholinergic (Furshpan et al., 1976; Potter et al., 1981; Landis and Keefe, 1983; Wolinsky and Patterson, 1983; Schafer et al., 1997, 1998; Francis and Landis, 1999; Yang et al., 2002; Weihe et al., 2005). Thus, the VAChT-positive fibers in hippocampus may arise from a gain of cholinergic function or an adrenergic to cholinergic phenotype switch. This idea is supported by the fact that NGF, which triggers sympathetic ingrowth after septal lesion (Crutcher, 1987), can also induce sympathetic neurons to undergo a phenotype switch (Landis et al., 1985; Madziar et al., 2005). We do not find costaining of VAChT and TH in single fibers, suggesting no gain of cholinergic function by noradrenergic SCG neurons. However, this does not rule out a phenotype switch, which might be undetectable if $\mathrm{TH}$ expression decreases before VAChT expression becomes measurable. Alternatively, VAChT-positive fibers possibly arise from selective sprouting of SCG neurons that normally have a cholinergic phenotype, although these neurons make up $<1 \%$ of the total SCG neuron population (Schafer et al., 1998).

Another possibility is that adrenergic sympathetic sprouting stimulates sprouting of cholinergic parasympathetic axons that innervate the cerebral vasculature (Suzuki et al., 1990). This would require the release of a factor from the sprouted SCG axons near the parasympathetic axons to stimulate their sprouting. Interactions between the sympathetic and parasympathetic systems have been reported previously (Hasan and Smith, 2000; Smith et al., 2002); however, there is no information that sympathetic sprouting can induce parasympathetic sprouting. Furthermore, the rapid loss of the new cholinergic fibers after unilateral ganglionectomy argues against this mechanism because it would require that the adrenergic sympathetic fibers degenerate quickly enough for the parasympathetic fibers to feel the absence of the factor and degenerate, all in the space of $5 \mathrm{~d}$. This is unlikely, because our immunohistochemistry data show that it takes $>3 \mathrm{~d}$, and perhaps as long as $10 \mathrm{~d}$, for central cholinergic fibers to completely degenerate after electrolytic lesion of medial septum.

The cholinergic reinnervation we observe after medial septal lesion could also occur as a consequence of hippocampal cholinergic denervation induced by fimbria-fornix lesion, because this lesion method also stimulates adrenergic sympathetic sprouting (Loy and Moore, 1977; Crutcher, 1987; Jackisch et al., 1999). Because the density of VAChT-positive boutons is modest, reaching only $\sim 15 \%$ of normal innervation, we speculate that previous studies using both septal and fimbria-fornix lesions assumed that the cholinergic innervation remaining after lesion is central fibers that have escaped injury. Importantly, the impact of this modest cholinergic reinnervation is powerful, and as we report here, its compensatory effects on mLTD expression can only be noticed after bilateral superior cervical ganglionectomy. Future studies should consider possible compensatory effects of this sympathetic driven cholinergic reinnervation. Potentially, this reinnervation could explain why some studies have not observed negative effects of central cholinergic lesions on hippocampal-dependent learning.

\section{Altered $M_{1}$ signaling after cholinergic denervation and ingrowth}

In hippocampus, several studies show that $\mathrm{M}_{1}$ receptor-Gq coupling and subsequent PI turnover is compromised in humans 
with $\mathrm{AD}$ and in animal models after loss of cholinergic innervation (Pearce and Potter, 1991; Ferrari-DiLeo and Flynn, 1993; Ferrari-DiLeo et al., 1995; Ladner et al., 1995; Ladner and Lee, 1998; Potter et al., 1999, 2002; Muma et al., 2003; Kelly et al., 2005). However, in cortex, muscarinic stimulation of PI turnover after lesion of the cholinergic basal forebrain is much less affected (Rossner et al., 1995), which could result from activity of cholinergic interneurons in cortex that maintains receptor coupling. Thus, we hypothesize that, although the density of the newly sprouted cholinergic fibers in hippocampus is quite low, they must provide enough cholinergic activity to reestablish $M_{1}$ receptor-Gq coupling and rescue mLTD. This seems plausible because maximal stimulation of PI hydrolysis occurs by stimulating only $15 \%$ of the total number of $M_{1}$ receptors expressed in hippocampus (Porter et al., 2002). The tight temporal relationship between the rescue of mLTD expression and the reappearance of VAChTpositive boutons throughout hippocampus lends strong support to the idea that the cholinergic reinnervation is causal to mLTD rescue. Our findings imply that the limiting factor in mLTD induction is efficient $M_{1}$ receptor-G-protein coupling, because the number of $M_{1}$ receptor binding sites increases in response to cholinergic denervation (Harrell et al., 1995; Rossner et al., 1995). However, NE LTD requires Gq-coupled $\alpha 1$ adrenergic receptors, yet it is still present in slices from animals without ingrowth that do not express mLTD. This underscores the fact that the molecules downstream of $\mathrm{M}_{1}$ receptors are available and function, strengthening the idea that the defect must be at the level of $\mathrm{M}_{1}-\mathrm{Gq}$ coupling. In addition, the lack of a deficit in LTP and LFS-LTD in this experimental group demonstrates that the synapses are not generally impaired in their ability to express plasticity. These data indicate that the deficit is specific for $M_{1}$ receptor-dependent LTD expression.

It is interesting to note that the transient presynaptic depression during CCh application, which is mediated in part by $\mathrm{M}_{3}$ receptors, is unchanged in all experimental animal groups (Fig. $3 A, B)$. Together, these data show that $\mathrm{M}_{3}$ receptors do not require intact cholinergic innervation to maintain efficient coupling. Therefore, not all cholinergic mechanisms are impaired by cholinergic denervation. Why $\mathrm{M}_{3}$ receptors are resistant to uncoupling after loss of acetylcholine is currently not understood. Perhaps the geometry or lipid composition of the presynaptic terminal in the vicinity of $\mathrm{M}_{3}$ receptors somehow protects them from becoming uncoupled from $\mathrm{Gq}$ during loss of agonist; however, this remains to be determined.

\section{Cholinergic innervation and synaptic plasticity}

$M_{1}$ receptors have been implicated in cholinergic-dependent cognitive processes (Bodick et al., 1997; Ghelardini et al., 1999; Anagnostaras et al., 2003). Knock-down or knock-out of $M_{1}$ receptors impairs memory formation in rodents (Ghelardini et al., 1999; Anagnostaras et al., 2003). Because mLTD is mediated by $\mathrm{M}_{1}$ receptors, this synaptic modulation may be a mechanism by which these receptors affect cognition.

The role of LTD as a substrate for learning and memory is beginning to be appreciated (Xu et al., 1998; Braunewell and Manahan-Vaughan, 2001). Exposure to a novel environment enhances the induction of LTD in the CA1 region (ManahanVaughan and Braunewell, 1999), emphasizing the important role of LTD in this learning behavior. In addition, impairment of LTD correlates with poor spatial memory (Nakao et al., 2002; Lee et al., 2003). Thus, a form of LTD dependent on cholinergic modulation of hippocampal synaptic function, as reported here, may be critical for normal learning and memory. This is supported by the work of Hasselmo and colleagues (for review, see Hasselmo, 1999), which demonstrates that cholinergic suppression of excitatory transmission in hippocampus is critical for encoding new information because it prevents interference from previously encoded memories.

$\mathrm{M}_{1}$ receptor signaling is altered in AD (Ladner et al., 1995), which is believed to contribute to memory deficits. Furthermore, $M_{1}$ receptors appear to be a useful target for AD therapy (Bodick et al., 1997; Fisher et al., 2003). Because sympathetic ingrowth impacts $M_{1}$ receptor function, and it has been found in hippocampus of some AD patients (Booze et al., 1993), a better understanding of the cellular mechanisms that both encourage and inhibit sprouting, as well as how synaptic function is modulated as a result, could have significant clinical impact for neurodegenerative diseases involving the cholinergic system.

\section{References}

Alkondon M, Albuquerque EX (2004) The nicotinic acetylcholine receptor subtypes and their function in the hippocampus and cerebral cortex. Prog Brain Res 145:109-120.

Anagnostaras SG, Murphy GG, Hamilton SE, Mitchell SL, Rahnama NP, Nathanson NM, Silva AJ (2003) Selective cognitive dysfunction in acetylcholine M1 muscarinic receptor mutant mice. Nat Neurosci 6:51-58.

Atri A, Sherman S, Norman KA, Kirchhoff BA, Nicolas MM, Greicius MD, Cramer SC, Breiter HC, Hasselmo ME, Stern CE (2004) Blockade of central cholinergic receptors impairs new learning and increases proactive interference in a word paired-associate memory task. Behav Neurosci 118:223-236.

Auerbach JM, Segal M (1994) A novel cholinergic induction of long-term potentiation in rat hippocampus. J Neurophysiol 72:2034-2040.

Auerbach JM, Segal M (1996) Muscarinic receptors mediating depression and long-term potentiation in rat hippocampus. J Physiol 492:479-493.

Ayyagari PV, Harrell LE, Parsons DS, Kolasa K (1996) Sympathetic sprouting reverses decreases in membrane-associated activity of protein kinase $\mathrm{C}$ following septohippocampal denervation of the rat hippocampus. Brain Res 708:205-208.

Berger-Sweeney J, Heckers S, Mesulam MM, Wiley RG, Lappi DA, Sharma M (1994) Differential effects on spatial navigation of immunotoxininduced cholinergic lesions of the medial septal area and nucleus basalis magnocellularis. J Neurosci 14:4507-4519.

Bierer LM, Haroutunian V, Gabriel S, Knott PJ, Carlin LS, Purohit DP, Perl DP, Schmeidler J, Kanof P, Davis KL (1995) Neurochemical correlates of dementia severity in Alzheimer's disease: relative importance of the cholinergic deficits. J Neurochem 64:749-760.

Bliss TV, Collingridge GL (1993) A synaptic model of memory: long-term potentiation in the hippocampus. Nature 361:31-39.

Bodick NC, Offen WW, Levey AI, Cutler NR, Gauthier SG, Satlin A, Shannon HE, Tollefson GD, Rasmussen K, Bymaster FP, Hurley DJ, Potter WZ, Paul SM (1997) Effects of xanomeline, a selective muscarinic receptor agonist, on cognitive function and behavioral symptoms in Alzheimer disease. Arch Neurol 54:465-473.

Booze RM, Mactutus CF, Gutman CR, Davis JN (1993) Frequency analysis of catecholamine axonal morphology in human brain. II. Alzheimer's disease and hippocampal sympathetic ingrowth. J Neurol Sci 119:110-118.

Braunewell KH, Manahan-Vaughan D (2001) Long-term depression: a cellular basis for learning? Rev Neurosci 12:121-140.

Collins F, Crutcher KA (1985) Neurotrophic activity in the adult rat hippocampal formation: regional distribution and increase after septal lesion. J Neurosci 5:2809-2814.

Crutcher KA (1987) Sympathetic sprouting in the central nervous system: a model for studies of axonal growth in the mature mammalian brain. Brain Res 434:203-233.

Crutcher KA, Brothers L, Davis JN (1981) Sympathetic noradrenergic sprouting in response to central cholinergic denervation; a histochemical study of neuronal sprouting in the rat hippocampal formation. Brain Res 210:115-128.

Dobrunz LE, Stevens CF (1997) Heterogeneity of release probability, facilitation, and depletion at central synapses. Neuron 18:995-1008. 
Drachman DA, Leavitt J (1974) Human memory and the cholinergic system. A relationship to aging? Arch Neurol 30:113-121.

Dudek SM, Bear MF (1992) Homosynaptic long-term depression in area CA1 of hippocampus and effects of $N$-methyl-D-aspartate receptor blockade. Proc Natl Acad Sci USA 89:4363-4367.

Ehlert FJ (1996) The interaction of 4-DAMP mustard with subtypes of the muscarinic receptor. Life Sci 58:1971-1978.

Ferguson SM, Savchenko V, Apparsundaram S, Zwick M, Wright J, Heilman CJ, Yi H, Levey AI, Blakely RD (2003) Vesicular localization and activity-dependent trafficking of presynaptic choline transporters. J Neurosci 23:9697-9709.

Fernandez De Sevilla D, Buno W (2003) Presynaptic inhibition of Schaffer collateral synapses by stimulation of hippocampal cholinergic afferent fibres. Eur J Neurosci 17:555-558.

Ferrari-DiLeo G, Flynn DD (1993) Diminished muscarinic receptorstimulated [3H]-PIP2 hydrolysis in Alzheimer's disease. Life Sci 53:PL439-PL444.

Ferrari-DiLeo G, Mash DC, Flynn DD (1995) Attenuation of muscarinic receptor-G-protein interaction in Alzheimer disease. Mol Chem Neuropathol 24:69-91.

Fisher A, Pittel Z, Haring R, Bar-Ner N, Kliger-Spatz M, Natan N, Egozi I, Sonego H, Marcovitch I, Brandeis R (2003) M1 muscarinic agonists can modulate some of the hallmarks in Alzheimer's disease: implications in future therapy. J Mol Neurosci 20:349-356.

Francis NJ, Landis SC (1999) Cellular and molecular determinants of sympathetic neuron development. Annu Rev Neurosci 22:541-566.

Furshpan EJ, MacLeish PR, O'Lague PH, Potter DD (1976) Chemical transmission between rat sympathetic neurons and cardiac myocytes developing in microcultures: evidence for cholinergic, adrenergic, and dualfunction neurons. Proc Natl Acad Sci USA 73:4225-4229.

Ghelardini C, Galeotti N, Matucci R, Bellucci C, Gualtieri F, Capaccioli S, Quattrone A, Bartolini A (1999) Antisense 'knockdowns' of M1 receptors induces transient anterograde amnesia in mice. Neuropharmacology 38:339-348.

Gu Z, Yu J, Perez-Polo JR (1998) Responses in the aged rat brain after total immunolesion. J Neurosci Res 54:7-16.

Harrell LE, Kolasa K, Parsons DS, Ayyagari V (1995) Hippocampal sympathetic ingrowth and cholinergic denervation uniquely alter muscarinic receptor subtypes in the hippocampus. Brain Res 676:386-393.

Harrell LE, Parsons D, Kolasa K (2001) Hippocampal sympathetic ingrowth occurs following 192-IgG-Saporin administration. Brain Res 911:158-162.

Harrell LE, Parsons DS, Kolasa K (2005) The effect of central cholinergic and noradrenergic denervation on hippocampal sympathetic ingrowth and apoptosis-like reactivity in the rat. Brain Res 1033:68-77.

Hasan W, Smith PG (2000) Nerve growth factor expression in parasympathetic neurons: regulation by sympathetic innervation. Eur J Neurosci 12:4391-4397.

Hasselmo ME (1999) Neuromodulation: acetylcholine and memory consolidation. Trends Cogn Sci 3:351-359.

Heckers S, Ohtake T, Wiley RG, Lappi DA, Geula C, Mesulam MM (1994) Complete and selective cholinergic denervation of rat neocortex and hippocampus but not amygdala by an immunotoxin against the p75 NGF receptor. J Neurosci 14:1271-1289.

Hortnagl H, Hellweg R (1997) Insights into the role of the cholinergic component of the septohippocampal pathway: what have we learned from experimental lesion studies? Brain Res Bull 43:245-255.

Hu L, Wong TP, Cote SL, Bell KF, Cuello AC (2003) The impact of Abetaplaques on cortical cholinergic and non-cholinergic presynaptic boutons in Alzheimer's disease-like transgenic mice. Neuroscience 121:421-432.

Huerta PT, Lisman JE (1993) Heightened synaptic plasticity of hippocampal CA1 neurons during a cholinergically induced rhythmic state. Nature 364:723-725.

Jackisch R, Stemmelin J, Neufang B, Lauth D, Neughebauer B, Kelche C, Cassel JC (1999) Sympathetic sprouting: no evidence for muscarinic modulation of noradrenaline release in hippocampal slices of rats with fimbria-fornix lesions. Exp Brain Res 124:17-24.

Karadsheh MS, Shah MS, Tang X, Macdonald RL, Stitzel JA (2004) Functional characterization of mouse alpha4beta2 nicotinic acetylcholine receptors stably expressed in HEK293T cells. J Neurochem 91:1138-1150.

Kelly JF, Storie K, Skamra C, Bienias J, Beck T, Bennett DA (2005) Relation- ship between Alzheimer's disease clinical stage and Gq/11 in subcellular fractions of frontal cortex. J Neural Transm 112:1049-1056.

Kesner RP, Adelstein TB, Crutcher KA (1989) Equivalent spatial location memory deficits in rats with medial septum or hippocampal formation lesions and patients with dementia of the Alzheimer's type. Brain Cogn 9:289-300.

Kirkwood A, Rozas C, Kirkwood J, Perez F, Bear MF (1999) Modulation of long-term synaptic depression in visual cortex by acetylcholine and norepinephrine. J Neurosci 19:1599-1609.

Kiss JP, Vizi ES, Westerink BH (1999) Effect of neostigmine on the hippocampal noradrenaline release: role of cholinergic receptors. NeuroReport 10:81-86

Kolasa K, Harrell LE, Parsons DS (1995) The effect of hippocampal sympathetic ingrowth and cholinergic denervation on hippocampal M2 cholinergic receptors. Brain Res 684:201-205.

Kolasa K, Harrell LE, Parsons DS (1997) Effect of hippocampal sympathetic ingrowth and cholinergic denervation on hippocampal phospholipase $\mathrm{C}$ activity and G-protein function. Neuroscience 77:111-120.

Kolasa K, Parsons DS, Harrell LE (2000) Effect of phospholipase C and protein kinase $\mathrm{C}$ following cholinergic denervation and hippocampal sympathetic ingrowth in rat hippocampus. Neuroscience 99:25-31.

Kremin T, Gerber D, Giocomo LM, Huang SY, Tonegawa S, Hasselmo ME (2005) Muscarinic suppression in stratum radiatum of CA1 shows dependence on presynaptic M1 receptors and is not dependent on effects at GABA(B) receptors. Neurobiol Learn Mem 85:153-163.

Ladner CJ, Lee JM (1998) Pharmacological drug treatment of Alzheimer disease: the cholinergic hypothesis revisited. J Neuropathol Exp Neurol 57:719-731.

Ladner CJ, Celesia GG, Magnuson DJ, Lee JM (1995) Regional alterations in M1 muscarinic receptor-G protein coupling in Alzheimer's disease. J Neuropathol Exp Neurol 54:783-789.

Landis SC, Keefe D (1983) Evidence for neurotransmitter plasticity in vivo: developmental changes in properties of cholinergic sympathetic neurons. Dev Biol 98:349-372.

Landis SC, Fredieu JR, Yodlowski M (1985) Neonatal treatment with nerve growth factor antiserum eliminates cholinergic sympathetic innervation of rat sweat glands. Dev Biol 112:222-229.

Lee HK, Takamiya K, Han JS, Man H, Kim CH, Rumbaugh G, Yu S, Ding L, He C, Petralia RS, Wenthold RJ, Gallagher M, Huganir RL (2003) Phosphorylation of the AMPA receptor GluR1 subunit is required for synaptic plasticity and retention of spatial memory. Cell 112:631-643.

Loy R, Moore RY (1977) Anomalous innervation of the hippocampal formation by peripheral sympathetic axons following mechanical injury. Exp Neurol 57:645-650.

Madziar B, Lopez-Coviella I, Zemelko V, Berse B (2005) Regulation of cholinergic gene expression by nerve growth factor depends on the phosphatidylinositol-3'-kinase pathway. J Neurochem 92:767-779.

Malenka RC, Bear MF (2004) LTP and LTD: an embarrassment of riches. Neuron 44:5-21.

Manahan-Vaughan D, Braunewell KH (1999) Novelty acquisition is associated with induction of hippocampal long-term depression. Proc Natl Acad Sci USA 96:8739-8744.

Marino MJ, Rouse ST, Levey AI, Potter LT, Conn PJ (1998) Activation of the genetically defined m1 muscarinic receptor potentiates $N$-methyl-Daspartate (NMDA) receptor currents in hippocampal pyramidal cells. Proc Natl Acad Sci USA 95:11465-11470.

Massey PV, Bhabra G, Cho K, Brown MW, Bashir ZI (2001) Activation of muscarinic receptors induces protein synthesis-dependent long-lasting depression in the perirhinal cortex. Eur J Neurosci 14:145-152.

Max SI, Liang JS, Potter LT (1993a) Purification and properties of m1toxin, a specific antagonist of $\mathrm{m} 1$ muscarinic receptors. J Neurosci 13:4293-4300.

Max SI, Liang JS, Valentine HH, Potter LT (1993b) Use of ml-toxin as a selective antagonist of $\mathrm{m} 1$ muscarinic receptors. J Pharmacol Exp Ther 267:480-485.

McGaughy J, Dalley JW, Morrison CH, Everitt BJ, Robbins TW (2002) Selective behavioral and neurochemical effects of cholinergic lesions produced by intrabasalis infusions of 192 IgG-saporin on attentional performance in a five-choice serial reaction time task. J Neurosci 22:1905-1913.

Muma NA, Mariyappa R, Williams K, Lee JM (2003) Differences in regional and subcellular localization of G(q/11) and RGS4 protein levels in Alzhei- 
mer's disease: correlation with muscarinic M1 receptor binding parameters. Synapse 47:58-65.

Naik N (1963) Technical variations in Koelle's histochemical method for demonstrating cholinesterase activity. Q J Microsc Sci 104:89-100.

Nakao K, Ikegaya Y, Yamada MK, Nishiyama N, Matsuki N (2002) Hippocampal long-term depression as an index of spatial working memory. Eur J Neurosci 16:970-974.

Nilsson OG, Leanza G, Bjorklund A (1992) Acetylcholine release in the hippocampus: regulation by monoaminergic afferents as assessed by in vivo microdialysis. Brain Res 584:132-140.

Pearce BD, Potter LT (1991) Coupling of $\mathrm{m} 1$ muscarinic receptors to G protein in Alzheimer disease. Alzheimer Dis Assoc Disord 5:163-172.

Pitler TA, Alger BE (1992) Cholinergic excitation of GABAergic interneurons in the rat hippocampal slice. J Physiol 450:127-142.

Porter AC, Bymaster FP, DeLapp NW, Yamada M, Wess J, Hamilton SE, Nathanson NM, Felder CC (2002) M1 muscarinic receptor signaling in mouse hippocampus and cortex. Brain Res 944:82-89.

Potter DD, Landis SC, Furshpan EJ (1981) Adrenergic-cholinergic dual function in cultured sympathetic neurons of the rat. Ciba Found Symp $83: 123-138$

Potter LT (2001) Snake toxins that bind specifically to individual subtypes of muscarinic receptors. Life Sciences 68:2541-2547.

Potter PE, Gaughan C, Assouline Y (1999) Lesion of septal-hippocampal neurons with 192 IgG-saporin alters function of M1 muscarinic receptors. Neuropharmacology 38:579-586.

Rossner S, Schliebs R, Hartig W, Bigl V (1995) 192IGG-saporin-induced selective lesion of cholinergic basal forebrain system: neurochemical effects on cholinergic neurotransmission in rat cerebral cortex and hippocampus. Brain Res Bull 38:371-381.

Rovira C, Ben-Ari Y, Cherubini E (1983) Dual cholinergic modulation of hippocampal somatic and dendritic field potentials by the septohippocampal pathway. Exp Brain Res 49:151-155.

Schafer MK, Schutz B, Weihe E, Eiden LE (1997) Target-independent cholinergic differentiation in the rat sympathetic nervous system. Proc Natl Acad Sci USA 94:4149-4154.

Schafer MK, Eiden LE, Weihe E (1998) Cholinergic neurons and terminal fields revealed by immunohistochemistry for the vesicular acetylcholine transporter. II. The peripheral nervous system. Neuroscience 84:361-376.
Scheiderer CL, Dobrunz LE, McMahon LL (2004) Novel form of long-term synaptic depression in rat hippocampus induced by activation of alpha 1 adrenergic receptors. J Neurophysiol 91:1071-1077.

Shinoe T, Matsui M, Taketo MM, Manabe T (2005) Modulation of synaptic plasticity by physiological activation of M1 muscarinic acetylcholine receptors in the mouse hippocampus. J Neurosci 25:11194-11200.

Smith PG, Warn JD, Steinle JJ, Krizsan-Agbas D, Hasan W (2002) Modulation of parasympathetic neuron phenotype and function by sympathetic innervation. Auton Neurosci 96:33-42.

Stenevi U, Bjorklund A (1978) Growth of vascular sympathetic axons into the hippocampus after lesions of the septo-hippocampal pathway: a pitfall in brain lesion studies. Neurosci Lett 7:219-224.

Suzuki N, Hardebo JE, Owman C (1990) Origins and pathways of choline acetyltransferase-positive parasympathetic nerve fibers to cerebral vessels in rat. J Cereb Blood Flow Metab 10:399-408.

Valentino RJ, Dingledine R (1981) Presynaptic inhibitory effect of acetylcholine in the hippocampus. J Neurosci 1:784-792.

Weihe E, Schutz B, Hartschuh W, Anlauf M, Schafer MK, Eiden LE (2005) Coexpression of cholinergic and noradrenergic phenotypes in human and nonhuman autonomic nervous system. J Comp Neurol 492:370-379.

Williams JH, Kauer JA (1997) Properties of carbachol-induced oscillatory activity in rat hippocampus. J Neurophysiol 78:2631-2640.

Wolinsky E, Patterson PH (1983) Tyrosine hydroxylase activity decreases with induction of cholinergic properties in cultured sympathetic neurons. J Neurosci 3:1495-1500.

Wong TP, Debeir T, Duff K, Cuello AC (1999) Reorganization of cholinergic terminals in the cerebral cortex and hippocampus in transgenic mice carrying mutated presenilin-1 and amyloid precursor protein transgenes. J Neurosci 19:2706-2716.

Xu L, Anwyl R, Rowan MJ (1998) Spatial exploration induces a persistent reversal of long-term potentiation in rat hippocampus. Nature 394:891-894.

Yang B, Slonimsky JD, Birren SJ (2002) A rapid switch in sympathetic neurotransmitter release properties mediated by the $\mathrm{p} 75$ receptor. Nat Neurosci 5:539-545.

Zucker RS (1989) Short-term synaptic plasticity. Annu Rev Neurosci 12 $13-31$. 